\title{
Genome-wide association study for salinity tolerance at the flowering stage in a panel of rice accessions from Thailand
}

\author{
Chakkree Lekklar ${ }^{1,2}$, Monnat Pongpanich", ${ }^{3,4}$ Duangjai Suriya-arunroj ${ }^{5}$, Aumnart Chinpongpanich ${ }^{6}$, Helen Tsai ${ }^{7}$, \\ Luca Comai ${ }^{7}$, Supachitra Chadchawan ${ }^{2,4}$ and Teerapong Buaboocha ${ }^{2,4,6^{*}}$ (D)
}

\begin{abstract}
Background: Salt stress, a major plant environmental stress, is a critical constraint for rice productivity. Dissecting the genetic loci controlling salt tolerance in rice for improving productivity, especially at the flowering stage, remains challenging. Here, we conducted a genome-wide association study (GWAS) of salt tolerance based on exome sequencing of the Thai rice accessions.

Results: Photosynthetic parameters and cell membrane stability under salt stress at the flowering stage; and yieldrelated traits of 104 Thai rice (Oryza sativa L.) accessions belonging to the indica subspecies were evaluated. The rice accessions were subjected to exome sequencing, resulting in 112,565 single nucleotide polymorphisms (SNPs) called with a minor allele frequency of at least 5\%. LD decay analysis of the panel indicates that the average LD for SNPs at $20 \mathrm{~kb}$ distance from each other was $0.34\left(r^{2}\right)$, which decayed to its half value $(\sim 0.17)$ at around $80 \mathrm{~kb}$. By GWAS performed using mixed linear model, two hundred loci containing 448 SNPs on exons were identified based on the salt susceptibility index of the net photosynthetic rate at day 6 after salt stress; and the number of panicles, filled grains and unfilled grains per plant. One hundred and forty six genes, which accounted for $73 \%$ of the identified loci, colocalized with the previously reported salt quantitative trait loci (QTLS). The top four regions that contained a high number of significant SNPs were found on chromosome 8, 12, 1 and 2. While many are novel, their annotation is consistent with potential involvement in plant salt tolerance and in related agronomic traits. These significant SNPS greatly help narrow down the region within these QTLs where the likely underlying candidate genes can be identified.

Conclusions: Insight into the contribution of potential genes controlling salt tolerance from this GWAS provides further understanding of salt tolerance mechanisms of rice at the flowering stage, which can help improve yield productivity under salinity via gene cloning and genomic selection.
\end{abstract}

Keywords: Rice, Salt tolerance, Flowering stage, Genome-wide association study

\section{Background}

Stress caused by salinity is one of the most serious environmental factors, which inhibits plant growth and decreases crop productivity worldwide [1]. Primary effects occurring at the beginning of salt stress include retarded cell division and expansion [2], stomata closure and photosynthesis reduction [3]. During long-term exposure to salt stress,

\footnotetext{
* Correspondence: Teerapong.B@chula.ac.th

${ }^{2}$ Center of Excellent in Environment and Plant Physiology, Department of Botany, Faculty of Science, Chulalongkorn University, Bangkok, Thailand

${ }^{4}$ Omics Sciences and Bioinformatics Center, Faculty of Science,

Chulalongkorn University, Bangkok, Thailand

Full list of author information is available at the end of the article
}

accumulation of salt ions in plant aerial parts via the transpiration stream leads to ionic stress $[1,2,4]$. To adaptively respond and survive under salinity, plants require changes of various cellular, physiological and metabolic mechanisms, which are controlled by the regulated expression of specific stress-related genes through cascades of complex regulatory networks [5-7].

Rice (Oryza sativa L.), one of the world's most important cereal crops, is classified as a salinity sensitive crop $[1,8]$. An electrical conductivity (EC) of $\sim 6 \mathrm{dS} \mathrm{m}^{-1}(\sim 56.98 \mathrm{mM}$ $\mathrm{NaCl}$ [9]) would result in more than $50 \%$ reduction in yield of many rice varieties [10]. Therefore, plant breeders are

(c) The Author(s). 2019 Open Access This article is distributed under the terms of the Creative Commons Attribution 4.0 International License (http://creativecommons.org/licenses/by/4.0/), which permits unrestricted use, distribution, and reproduction in any medium, provided you give appropriate credit to the original author(s) and the source, provide a link to the Creative Commons license, and indicate if changes were made. The Creative Commons Public Domain Dedication waiver (http://creativecommons.org/publicdomain/zero/1.0/) applies to the data made available in this article, unless otherwise stated. 
continuously improving salt tolerant rice cultivars to increase yield productivity [11]. However, salt tolerance is a multigenic trait, which underlying mechanisms are controlled by many genes and affected by the environment. Breeding efforts for developing salt tolerant rice have been limited because the salt tolerance mechanisms and the genes that control them are not completely understood [12-14]. To fill the knowledge gap between genotypes and phenotypes of the salt stress response in rice, forward and reverse genetics have been performed to identify salt-responsive loci/genes such as genetic mapping of quantitative trait loci (QTLs) using cross population; screening of mutants generated by chemical- or irradiation-induced mutagenesis; and transgenic approach $[15,16]$. To identify salt-responsive genes using cross population, a number of mapping studies have identified QTLs of physiological traits related to salinity tolerance in economic crops such as soybean, barley and rice [17-19]. Although QTL mapping is a powerful and popular method to tag the salt tolerance region in plants, the examination of the variation is one of the limitation because QTL mapping can identify only allelic diversity that segregates between the parents of a particular $\mathrm{F}_{2}$ cross or within recombinant inbred lines and the mapping resolution is limited by the amount of the genetic recombination event occurring in the mapping populations [20, 21]. Moreover, the genotyping by SSR markers, which is usually based on polymerase chain reaction (PCR), is limiting to examining the kinds of variations, and laborious and time-consuming when high-density genotyping is needed for a large number of individuals [22].

Over the past several years, next generation sequencing has been used to rapidly generate a large amount of accurate genomic data, providing a powerful approach for functional genomics and molecular breeding studies, including the genome-wide association study (GWAS) [23]. GWAS, which is the analysis of the statistical association between genetic variants and traits on the whole genome scale in a large number of individuals within an organism, has been employed to identify causal genetic variability for target traits, including those in Arabidopsis and crop species [22, 24-26]. Compared with the QTL linkage mapping method, GWAS provides high resolution mapping using single nucleotide polymorphisms (SNPs) as genetic markers [22, 27]. GWAS in rice was performed for agronomic traits such as tiller number, grain width, grain length and spikelet number in the indica subspecies based on SNPs identified by whole-genome sequencing. $[28,29]$. In another report, the genetic architecture of rice chlorophyll content at the heading stage was revealed by GWAS. Forty-six significant loci were identified and Ghd7 was highlighted as a major locus for the natural variation of the chlorophyll content [30]. GWAS also revealed three QTLs (qER1-3) located on chromosomes 3, 6 and 12 associated with the responsiveness of yield-determination traits under field condition [31]. Application of GWAS for causative gene identification has been reported in rice responding to abiotic stresses such as aluminum, boron, cold, drought and salt stresses [32-36]. On salt stress, there are several GWA studies in rice with different growing stages and traits. Shi et al. [37] studies GWAS on germination stage of salt-treated rice using $\sim 6000,000$ SNPs, 11 loci containing 22 significant SNPs responsible for stress-susceptibility indices of the vigor index and germination time were identified. The strongest association region for germination time was detected on chromosome 1, near salt-tolerance QTL controlling $\mathrm{Na}^{+}$uptake and $\mathrm{K}^{+}$ concentration. At tillering stage, GWAS was performed on rice exposed to short- $(6 \mathrm{~h})$, medium- (7 d) and longterm (30 d) salt stress based on 200,000 SNPs. Around 1200 candidate genes associated with growth parameters, and $\mathrm{Na}^{+}$and $\mathrm{K}^{+}$content were identified [36]. For salttreated rice at reproductive stage, only a study of Kumar et al. [38] were reported. Based on 6000 SNPs, it was shown that 20 loci were associated with the $\mathrm{Na}^{+} / \mathrm{K}^{+}$ratio, and 44 loci were associated with other traits. Twelve association mappings with $\mathrm{Na}^{+} / \mathrm{K}^{+}$were located on chromosome 1 where Saltol, a major QTL that controls shoot $\mathrm{Na}^{+} / \mathrm{K}^{+}$homeostasis in rice at the seedling stage, is located. However, GWAS has not been applied for the analysis of photosynthetic and yield-related traits in rice exposed to salt stress at the flowering stage, which is a highly salt-sensitive stage. Additionally, no rice accession from Thailand where a large collection of diverse rice germplasms can provide new allelic diversity for salt tolerance [39], were analyzed by GWAS.

The objectives of this research were (1) to investigate and cluster Thai and Asian rice accessions based on physiological responses and yield-related traits under the salt-stress condition at the flowering stage and (2) to perform GWAS for these traits to identify regions/genes responsible for salt tolerance.

\section{Methods \\ Plant materials and growing conditions}

The association panel consisted of a diverse collection of 190 rice (O. sativa) cultivars including both standard salt-tolerant (Pokkali) and salt-sensitive (IR29) varieties. The rice accessions in this study were kindly provided by the Pathum Thani Rice Research Center (Additional file 1: Table S1). The experiment was designed with a randomized complete block design with four replications. According to the limitation of the time-consuming process of data collection, the experiment was performed in three separate sets of experiments. The standard salttolerant and salt-sensitive cultivars were included in every experimental set. Twenty-one day old seedlings were cultivated using a hydroponic system with WP No. 2 nutrient 
solution [40] and transplanted into pots containing soil $(5 \mathrm{~kg})$ and maintained until harvest. At heading stage in the flowering phase of each accession, water on the soil surface was drained before salt stress treatment. Rice plants were then watered with $900 \mathrm{~mL}$ of $150 \mathrm{mM} \mathrm{NaCl}$ solution to reach the desired final soil electrical conductivity (EC) of 8-9 dS $\mathrm{m}^{-1}$ and treated for 9 days. For the control condition, rice plants were treated by tap water for the same period. Water level was kept at $2 \mathrm{~cm}$ above the soil surface throughout the experimental period. To recover, tap water was used to wash out salt ions in the soil every day until the soil EC was lower than $2 \mathrm{dS} \mathrm{m}^{-1}$; this condition was maintained until harvest to collect yield-related traits. These experiments were conducted in the greenhouse facility at the Nakhon Ratchasima Rice Research Center, Rice Department, Ministry of Agriculture and Cooperatives. The air temperature was maximum at $32{ }^{\circ} \mathrm{C}$ with natural light and minimum at $21.1^{\circ} \mathrm{C}$ during the night. The average relative humidity was $72.5 \%$.

\section{Parameter collection for association analysis}

Photosynthetic parameters consisting of net photosynthetic rate $\left(P_{\mathrm{N}}\right)$, stomatal conductance $\left(g_{\mathrm{s}}\right)$, transpiration rate $(E)$, and intercellular $\mathrm{CO}_{2}$ concentration $\left(C_{\mathrm{i}}\right)$ were measured during the same period (8:30-11:30 a.m.) by the LI-6400 XT portable photosynthesis system (LI-COR, Lincoln, NE) on the middle portion of the 2nd leaf (penultimate leaf) of the main tiller on days $0,3,6$ and 9 after salt stress treatment. The photosynthetic photon flux density used was $1200 \mu \mathrm{mol}$ photon $\mathrm{m}^{-2} \mathrm{~s}^{-1}$. The leaf temperatures and ambient $\mathrm{CO}_{2}$ concentration used during the measurement were $27-30{ }^{\circ} \mathrm{C}$ and $380 \mathrm{ppm}$, respectively. A method modified from Blum and Ebercon [41] was used for cell membrane stability (CMS) measurement. One gram of the 2nd leaf was cut into segments of $2 \mathrm{~mm}$ in length and put into $10 \mathrm{ml}$ of deionized water in a test tube and left at room temperature for $2 \mathrm{~h}$. Electrical conductivity $\left(E C_{1}\right)$ of the sample solutions was measured using the universal instrument for measurements of conductivity (SevenCompact ${ }^{\mathrm{sm}}$ conductivity S230, Metler, USA). Then, the tissues in the test tubes were boiled for $15 \mathrm{~min}$, cooled to room temperature, and the final electrical conductivity $\left(\mathrm{EC}_{2}\right.$, maximum conductivity of the tissues) was measured. The percent CMS was calculated as $100 \times\left[100-\left(\mathrm{EC}_{1} / \mathrm{EC}_{2}\right.\right.$ ratio $\left.)\right]$. For yield-related traits, the numbers of tillers (TIL), panicles (PAN), filled grains (FG) and unfilled grains (UFG) per pot were recorded at the end of experiment.

\section{Exome library preparation}

Rice gDNA was extracted from leaf tissue using the Genomic DNA Mini Kit (Plant) (Geneaid Biotech Ltd., Taiwan) and the amount of DNA was quantified using a spectrophotometer. For the exome library preparation, gDNA was fragmented using dsDNA Fragmentase (New England Biolabs, Ipswich, MA). The sheared DNA was modified using an End Repaired enzyme (New England Biolabs) and deoxyadenosine was added at the 3 ' end using a Klenow fragment (New England Bio-labs). Each of the unique DNA barcodes (Bioo Scientific, Austin, TX) was joined to DNA in each library using DNA ligase (New England Biolabs). Pre-capture libraries were hybridized with the capture probes of the rice exome region, which were designed based on the O. sativa 'Nipponbare' database (Michigan State University [MSU] Rice Genome Annotation Project). The capture libraries were cleaned using AMPure (Beckman Coulter, Indianapolis, IN) and amplified by PCR using post-capture primers. The final yields were quantified by Bioanalyzer (Agilent Technologies, Santa Clara, CA). Exome-capture libraries (18-23) were pooled in each lane and sequenced using the Illumina HiSeq2000's protocol in the Illumina genome analyzer (San Diego, CA).

\section{Data analysis}

Statistical analysis of phenotypic traits

Statistical analyses were performed with IBP SPSS ver.22 (IBM Corp., Armonk, USA). Analysis of variance (ANOVA) was carried out to assess the effects of genotype, environment, and $\mathrm{G} \times \mathrm{E}$ interactions using the general linear model procedure. Duncan's Multiple Range Test was used to compare the mean value for tests of significance. Cluster analysis among physiological responses was performed by JMP ver. 11 (SAS Institute Inc., Cary NC, USA) and $\mathrm{R}$ 'corrplot' package [42].

\section{SNP genotyping and genotype data analysis}

The short-sequence reads from the Illumina Genome Analyzer were grouped into the correct categories using the pipeline created by Missirian et al. [43]. The rice reference genome was downloaded from the database (Ensemble version IRGSP-1.0), and indexed by SAMtools [44]. Raw reads were aligned against the reference genome using the Burrow-Wheeler Aligner (BWA version 0.5.7-1) [45]. Variants were called using genome analysis toolkit (GATK; version 3.3-0) [46]. Variants were filtered if they fitted the following criteria: to be called heterozygous, minimum coverage and minimum percentage of each of the two observed major basecalls were 5 and 20, respectively and minimum total coverage was 10 ; for a position to be called homozygous, minimum coverage was 6 or 3 if positions with the minimum coverage of 6 were present in at least 10 accessions. SNP density was visualized using $\mathrm{R}$ 'CMplot' (https://github.com/YinLiLin/R-CMplot).

\section{Population structure and linkage disequilibrium analysis}

To estimate the number of subgroups in the panel to select the appropriate statistical model for association between 
the phenotypic and genomic data, analysis of the population structure within the rice population was performed using EIGENSOFT version 6.0.1, which used principal component analysis (PCA) to model ancestry differences in a population $[47,48]$. Population stratification was visualized by plotting the first two PCs.

Linkage disequilibrium (LD) analysis was assessed by computing the correlation $\left(r^{2}\right)$ in frequency across a pair of SNP loci. The $r^{2}$ values between pairs of SNPs were calculated using the command in PLINK [49] --r2 -ld window-kb 2000 --ld-window 999999 --ld-window-r2 0. This command was used to calculate LD association among SNP pairs to a distance of $2000 \mathrm{~kb}$. LD decay analysis were conducted by division of marker pairs within the 2000-kb region into bins of $20 \mathrm{~kb}$ and $r^{2}$ values within each bin were averaged. To visualize the result, the $r^{2}$ values were sorted and plotted against the physical distance [38].

\section{Association mapping}

To identify loci underlying the genetic regulation of traits mentioned above, SNPs were removed from the analysis by PLINK 1.07 [49] if their minor allele frequency was less than $5 \%$ across the panel or the genotype was unknown for $>40 \%$ of the varieties. The resulting ungenotyped markers were imputed using Beagle 5.0 [50]. Genome-wide association (GWA) mapping was conducted using GEMMA software based on the SNP data and the phenotypic data $[51,52]$. To visualize the association results, the quantile-quantile (Q-Q) plots of observed $p$-values were constructed against expected $p$-values and Manhattan plots were constructed with the chromosome position on the X-axis against -log ( $p$-value) of all SNPs using the $\mathrm{R}$ 'qqman' package [53]. The $p$-value of SNP marker was corrected for multiple tests by calculating $q$-value (FDR adjusted $p$-value) of each trait. SNPs with the $q$-value lower than 0.05 was selected as significant marker.

\section{QTL analysis}

The list of candidate genes from GWA mapping was compared with the salt QTL mapping that was previously reported by $\mathrm{Hu}$ et al. [54], Patishtan et al. [36] and summarized in TropGENE [55], Gramene and http:// www.plantstress.com/files/qtls_for_resistance.htm\#salinity.

\section{Results}

\section{Phenotypic variation among Thai rice accessions under salt effect}

We evaluated photosynthetic parameters and cell membrane stability on 104 rice accessions individually at the flowering stage after salt stress for 3, 6 and 9 days and analyzed yield-related traits at harvesting time. The mean values and frequency distributions of all parameters of each accession are shown in Additional file 2: Table S2 and Additional file 3: Figure S1. The highest reduction of phenotypic traits was observed at day 9 after salt stress: photosynthetic rate, $P_{\mathrm{N}}(-49 \%)$; stomatal conductance, $g_{\mathrm{s}}(-50 \%)$; transpiration rate, $E(-43 \%)$, and cell membrane stability, CMS ($18 \%)$ when compared with the control condition (Table 1). However, we found that the mean values of intercellular $\mathrm{CO}_{2}$ concentration, $C_{\mathrm{i}}$ increased about $6 \%$ at day 9 after salt stress treatment. For yield-related traits, on average, number of tillers per plant, TIL; number of panicles per plant, PAN; number of filled grains per plant, FG decreased by 19, 11 and 26\%, respectively, whereas number of unfilled grains per plant, UFG increased by $10 \%$ (Table 1 ). To determine substantial genotypic variation in salt-stress responses, relative phenotypic values were calculated by the salt stability index of each rice accession [(salt/control) $x$ 100] (Fig. 1). These parameters tended to decrease when plants were exposed to salt stress, except $C_{\mathrm{i}}$, which tended to increase under salt stress. The variations of phenotypic traits were found in all parameters and were pronounced, particularly in the case of $P_{\mathrm{N}}$, FG and UFG (Fig. 1).

The relationships of the salt stability index of all parameters were determined by Pearson's correlation $r$ (Additional file 4: Table S3). We found a strong positive correlation between $P_{\mathrm{N}}$ and $g_{\mathrm{s}}$, or $E$ (Fig. 2). $P_{\mathrm{N}}$ also had a positive correlation with CMS, though weaker, at days 6 and 9 after salt treatment. Conversely, a strong negative correlation between $P_{\mathrm{N}}$ and $C_{\mathrm{i}}$ was found. As expected for yield-related traits, the strongest positive correlation was observed between TIL, PAN and UFG. In addition, the relationship between photosynthetic performance and yield-related traits were observed. TIL was negatively correlated with $g_{\mathrm{s}}$ at days 3 and 6; and with $E$ at day 3. Similarly, PAN was negatively correlated with $g_{\mathrm{s}}$ at day 3 as well as $P_{\mathrm{N}}$. Following the same trend, UFG was negatively correlated with $g_{\mathrm{s}}$ or $E$ at days 3 after salt treatment, and with $C_{\mathrm{i}}$ both at days 3 and 6. (Fig. 2 and Additional file 4: Table S3). In an opposite trend, a positive correlation was found between FG and $g_{\mathrm{s}}$ at day 6. At day 9 , no correlation was observed between photosynthetic parameters and yield-related traits.

\section{SNP data, population structure and LD pattern in the panel}

The list of rice accessions used for exome sequencing is shown in Additional file 1: Table S1. In total, 190 rice accessions were used for exome-sequencing, with the capture probes designed to cover about $50 \mathrm{Mb}$ of the nucleotide target covering all 12 chromosomes of rice. SNPs that showed a minor allele frequency (MAF) of $<5 \%$ of our population were removed to decrease overestimation of the effect of low-MAF SNPs. Therefore, the resultant number of 112,565 SNPs (Fig. 3), which were high-quality SNPs genotyped across this population, was subsequently used for GWAS. 
Table 1 Mean and range of phenotypic values and yield-related traits of 104 rice accessions. Mean phenotypic values of control and salt-treated plants $(n=104)$ are shown with the S.D

\begin{tabular}{|c|c|c|c|c|c|c|c|}
\hline Trait & DAT & Mean (Control) & Range & CV (\%) & Mean (Salt treated) & Range & CV (\%) \\
\hline \multirow[t]{3}{*}{$P_{\mathrm{N} \cdot \text { day6 }\left(\mu \mathrm{mol} \mathrm{CO}_{2} \mathrm{~m}^{-2} \mathrm{~s}^{-1}\right)}$} & 3 & $11.50 \pm 2.69$ & $5.78-19.86$ & 23.38 & $8.85 \pm 2.78$ & $3.28-16.40$ & 31.42 \\
\hline & 6 & $11.12 \pm 3.07$ & $5.20-19.89$ & 27.61 & $7.06 \pm 3.25$ & $1.20-16.56$ & 46.05 \\
\hline & 9 & $10.35 \pm 3.55$ & $2.97-22.16$ & 34.30 & $5.24 \pm 3.49$ & $0.17-14.36$ & 66.62 \\
\hline \multirow[t]{3}{*}{$g_{\mathrm{s}}\left(\mathrm{mol} \mathrm{CO} \mathrm{m}^{-2} \mathrm{~s}^{-1}\right)$} & 3 & $0.26 \pm 0.09$ & $0.11-0.56$ & 36.73 & $0.17 \pm 0.09$ & $0.05-0.50$ & 51.24 \\
\hline & 6 & $0.22 \pm 0.07$ & $0.08-0.46$ & 32.48 & $0.12 \pm 0.04$ & $0.04-0.22$ & 33.88 \\
\hline & 9 & $0.22 \pm 0.09$ & $0.08-0.48$ & 40.23 & $0.11 \pm 0.05$ & $0.03-0.26$ & 45.15 \\
\hline \multirow[t]{3}{*}{$E\left(\mathrm{mmol} \mathrm{H} \mathrm{H}_{2} \mathrm{~m}^{-2} \mathrm{~s}^{-1}\right)$} & 3 & $3.57 \pm 0.96$ & $1.42-5.67$ & 26.91 & $2.55 \pm 0.69$ & $1.16-4.21$ & 26.85 \\
\hline & 6 & $3.25 \pm 1.14$ & $1.19-5.62$ & 35.18 & $1.98 \pm 0.80$ & $0.61-3.78$ & 40.39 \\
\hline & 9 & $3.11 \pm 1.02$ & $1.18-5.65$ & 32.69 & $1.78 \pm 0.72$ & $0.66-3.58$ & 40.25 \\
\hline \multirow[t]{3}{*}{$C_{i}\left(\mu \mathrm{mol} \mathrm{mol}^{-1}\right)$} & 3 & $278.00 \pm 30.33$ & $214.95-335.38$ & 10.91 & $268.11 \pm 36.74$ & $204.88-335.50$ & 13.70 \\
\hline & 6 & $271.96 \pm 28.40$ & $194.33-316.75$ & 10.44 & $270.45 \pm 31.82$ & $205.16-327.75$ & 11.77 \\
\hline & 9 & $276.69 \pm 24.59$ & $218.85-315.75$ & 8.89 & $292.42 \pm 35.68$ & $227.79-366.62$ & 12.20 \\
\hline \multirow[t]{3}{*}{ CMS (\%) } & 3 & $88.33 \pm 3.78$ & $65.50-94.85$ & 4.28 & $85.42 \pm 5.70$ & $55.99-93.33$ & 6.67 \\
\hline & 6 & $88.79 \pm 3.48$ & $76.06-95.26$ & 3.92 & $80.13 \pm 8.30$ & 58.33-94.99 & 10.35 \\
\hline & 9 & $86.63 \pm 5.58$ & $62.07-93.88$ & 6.44 & $70.65 \pm 14.07$ & $29.54-90.83$ & 19.91 \\
\hline TIL & & $4.97 \pm 1.85$ & $2.41-9.41$ & 37.25 & $4.03 \pm 1.02$ & $2.58-7.77$ & 25.31 \\
\hline PAN & & $3.14 \pm 0.90$ & $1.33-6.10$ & 28.74 & $2.79 \pm 0.63$ & $1.67-5.17$ & 22.68 \\
\hline FG & & $44.12 \pm 28.68$ & $1.31-121.50$ & 65.01 & $32.78 \pm 26.60$ & $0.65-141.28$ & 81.15 \\
\hline UFG & & $88.89 \pm 33.55$ & $26.67-186.56$ & 37.74 & $97.82 \pm 38.45$ & $23.67-248.25$ & 39.30 \\
\hline
\end{tabular}
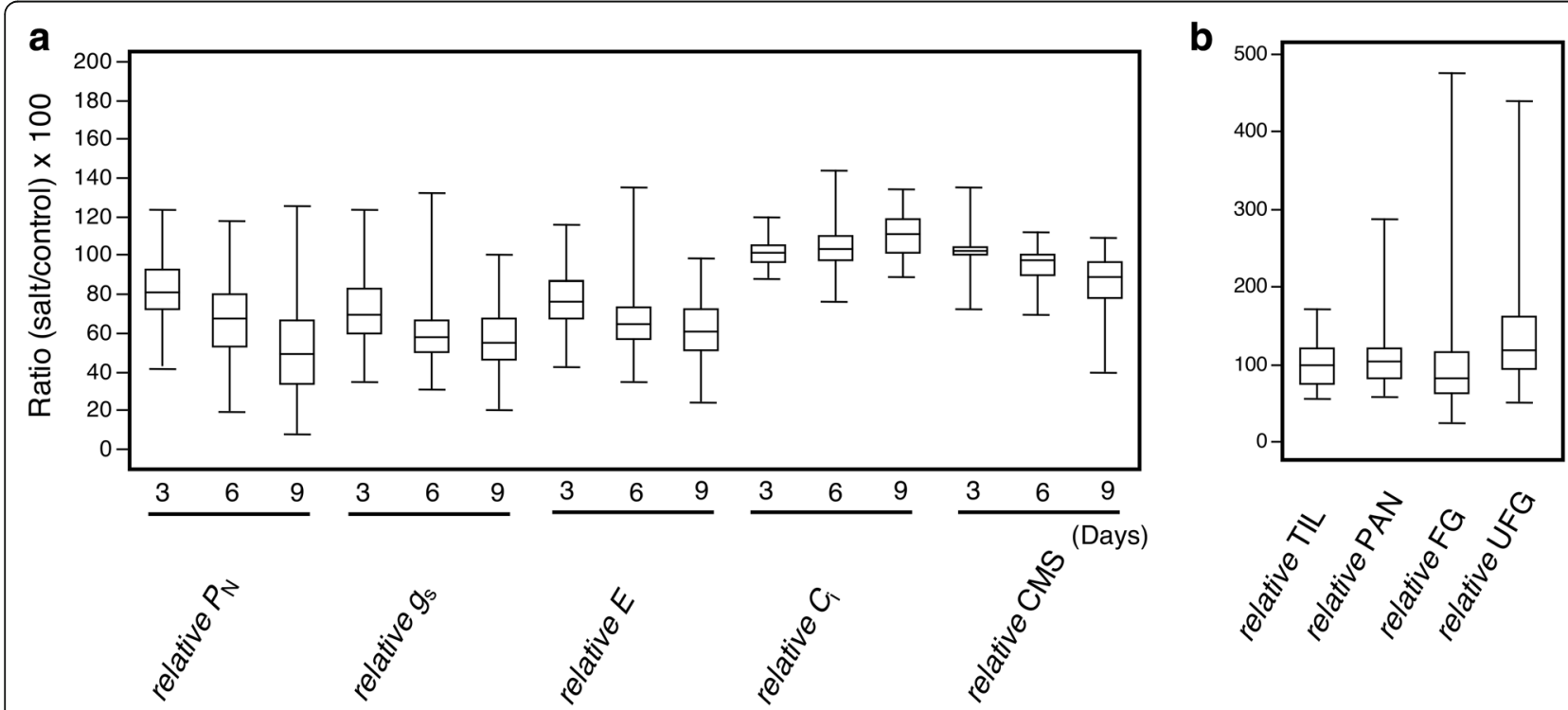

Fig. 1 Box plots for relative phenotypic values (a) and yield-related traits (b) (calculated as percent phenotypic value in salt divided by control condition). The median of each trait is shown as a horizontal bar in the box, and the upper and lower sides of a box represent the first and third quartile values of the distribution, respectively. Whiskers represented maximum/minimum values. $P_{\mathrm{N}}$ : net photosynthetic rate; $g_{\mathrm{s}}$ : Stomatal conductance; $E$ : Transpiration rate; $C_{i}$ : intercellular $\mathrm{CO}_{2}$ concentration; CMS: Cell membrane stability, TIL: number of tillers per plant; PAN: number of panicles per plant; FG: number of filled grains per plant and UFG: number of unfilled grains per plant 


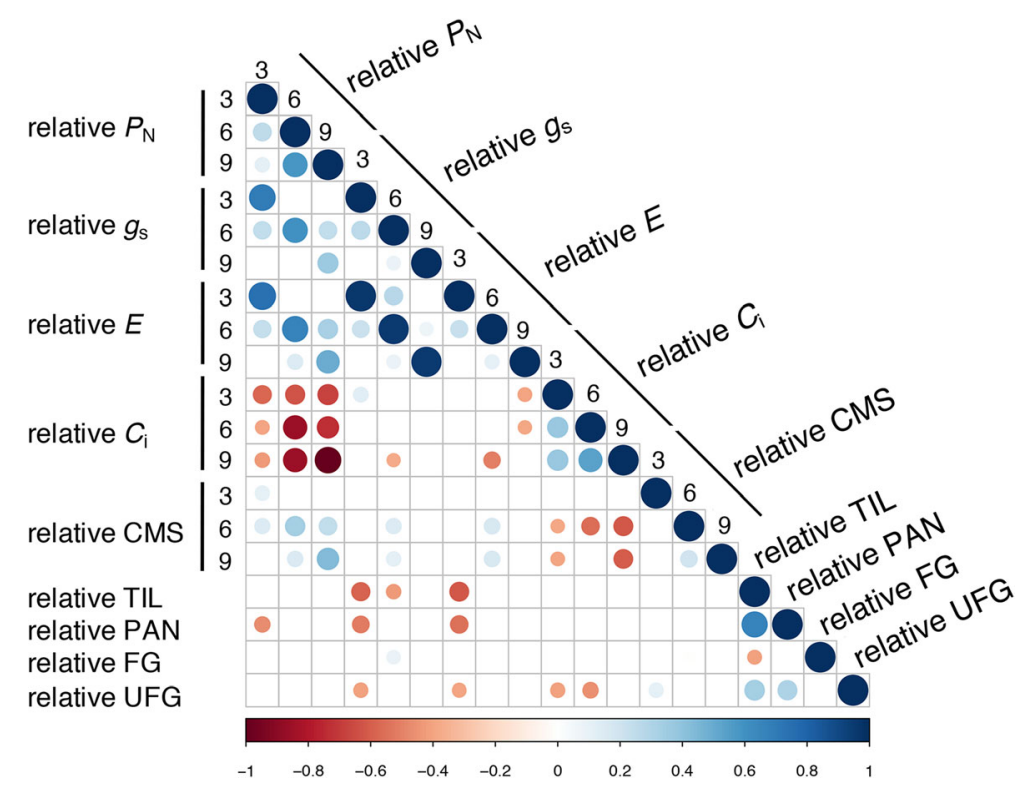

Fig. 2 Pearson correlation coefficients computed for susceptibility indices of all traits and timings. $P_{N}$ : net photosynthetic rate; $g_{s}$ : stomatal conductance; $E$ : transpiration rate; $C_{i}$ : intercellular $\mathrm{CO}_{2}$ concentration; CMS: cell membrane stability, TIL: numbers of tillers per plant; PAN: number of panicles per plant; FG: number of filled grains per plant and UFG: number of unfilled grains per plant. Cells with correlation values not significant at $p$-value $<0.05$ are left blank

EINGENSOFT was implemented for population structure analysis, which was based on PCA. Using SNPs identified by exome sequencing, two main subpopulations were delineated (Additional file 5: Figure S2), consisting of five accessions in the first group and 185 accessions in the second group, respectively. The rice accessions in the first group included 'Ai Tai, 'Jao Haw,' 'Beu Saw Mi, 'E-Puang' and 'Leung Tah Young' rice, which were grouped as upland rice (Additional file 1: Table S1). We also found that 'Pokkali' rice, which is a standard salt tolerance variety, was separated from the two main sub populations. Therefore, before association analysis, we removed upland

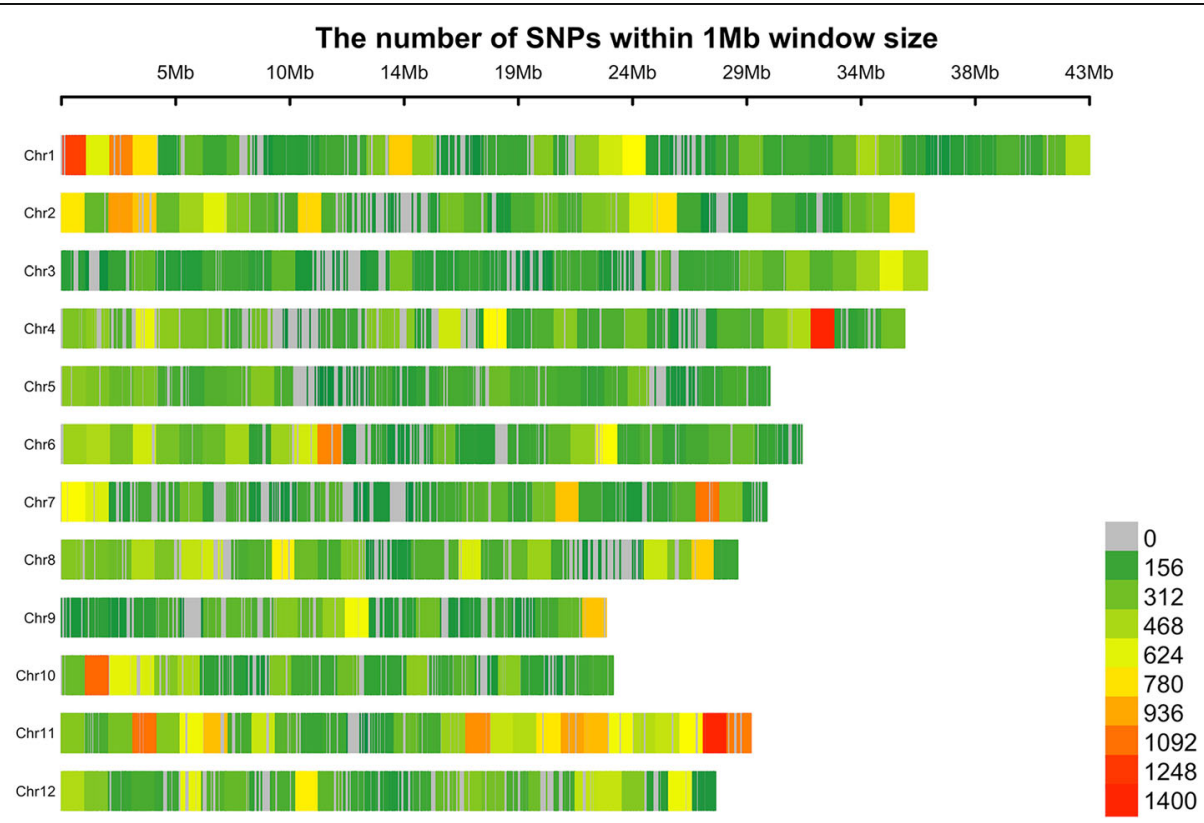

Fig. 3 The number of SNPs called using GATK within $1 \mathrm{Mb}$ window size in 12 rice chromosomes 
rice accessions to reduce strong subpopulation structure that may generate spurious association between the phenotype and unlinked SNP markers.

For LD decay analysis of the panel, the binned $r^{2}$ values were mapped against the physical distance and the distance at which the average of $r^{2}$ dropped to half of the maximum value was described as LD decay. The average LD for SNPs at $20 \mathrm{~kb}$ distance from each other was $0.34\left(r^{2}\right)$, which decayed to its half value $(\sim 0.17)$ at around $80 \mathrm{~kb}$ (Fig. 4). Additionally, PLINK was also used to calculate chromosome-wise LD between SNPs pairs. At $5 \mathrm{~kb}$ from each other, the greatest $r^{2}$ was found on chromosome $3\left(r^{2}=0.57\right)$ and the lowest $r^{2}$ was found on chromosome $11\left(r^{2}=0.27\right)$.

\section{Genome-wide association mapping and candidate loci associated with salt tolerance at flowering stage}

To identify potential genes associated with salt stress in Thai rice population, GWAS was performed using SNP data and the phenotypic data of 10 parameters by GEMMA software [51]. Manhattan plots were generated to illustrate the significance of exome-sequencing SNPs associated with each trait. Using the mixed linear model (MLM), after correction for multiple testing, markers with a $q$-value (an FDR adjusted $p$-value) $<0.05$ were considered as truly significant. Given that an FDR adjusted $p$-value threshold of 0.05 means that $5 \%$ of significant tests would result in false positives and the number of spurious associations was greatly reduced. Altogether, 448 significant SNPs were found from GWA mapping of four traits, and the list of SNP positions, alternate SNPs and candidate loci were presented in Additional file 6: Table S4. A significant SNP was found in the GWA mapping of net photosynthesis at day $6\left(P_{\mathrm{N}}\right.$.day6), which was located on chromosome 10 (Fig. 5a). There were two SNP peaks on the GWA mapping of PAN on chromosomes 2 and 10 (Fig. 5c). A SNP peak was also found in GWA mapping of FG, which was located on chromosome 4 (Fig. 5e) and there were four SNP peaks in the GWA mapping of UFG, which was on chromosomes 1, 7, 8 and 12 (Fig. 5g). The Q-Q plot of expected and observed $p$-values was delineated and SNPs that had $p$-values deviated from the linear indicated reasonable positives (Fig. 5b, d, f, h). Table 2 listed the loci identified by GWAS that contained multiple neighboring significant SNPs appeared and/or significant SNPs of low $p$-value. Figure 6 and Additional file 7: Figure S3a and $\mathrm{b}$ show the regions containing those significant SNPs with the shade color in the blue bar representing the pair-wise LD indicated by $r^{2}$ value for the SNP of the lowest $p$-value in that region.

\section{Comparison of the GWAS prediction and previously reported QTLs}

Overall, GWAS mapping identified 448 significant SNPs in the exome, which were located on 200 genes (Additional file 6: Table S4). Among these, there were 146 genes co-localized with salinity-related QTLs, which accounted for $73 \%$ of all candidate genes covering all rice chromosomes. Figure 7 represents salt-related QTL on which candidate genes were co-located. The top four regions that contained a high number of significant SNPs were found on chromosomes $8,12,1$ and 2, respectively (Table 3 ). The region containing the highest density of significant SNPs (100 SNPs) was located between markers RM7027 and RM826 on chromosome 8 , which was related with the salt evaluation score (SES) of rice [56]. The second highest density

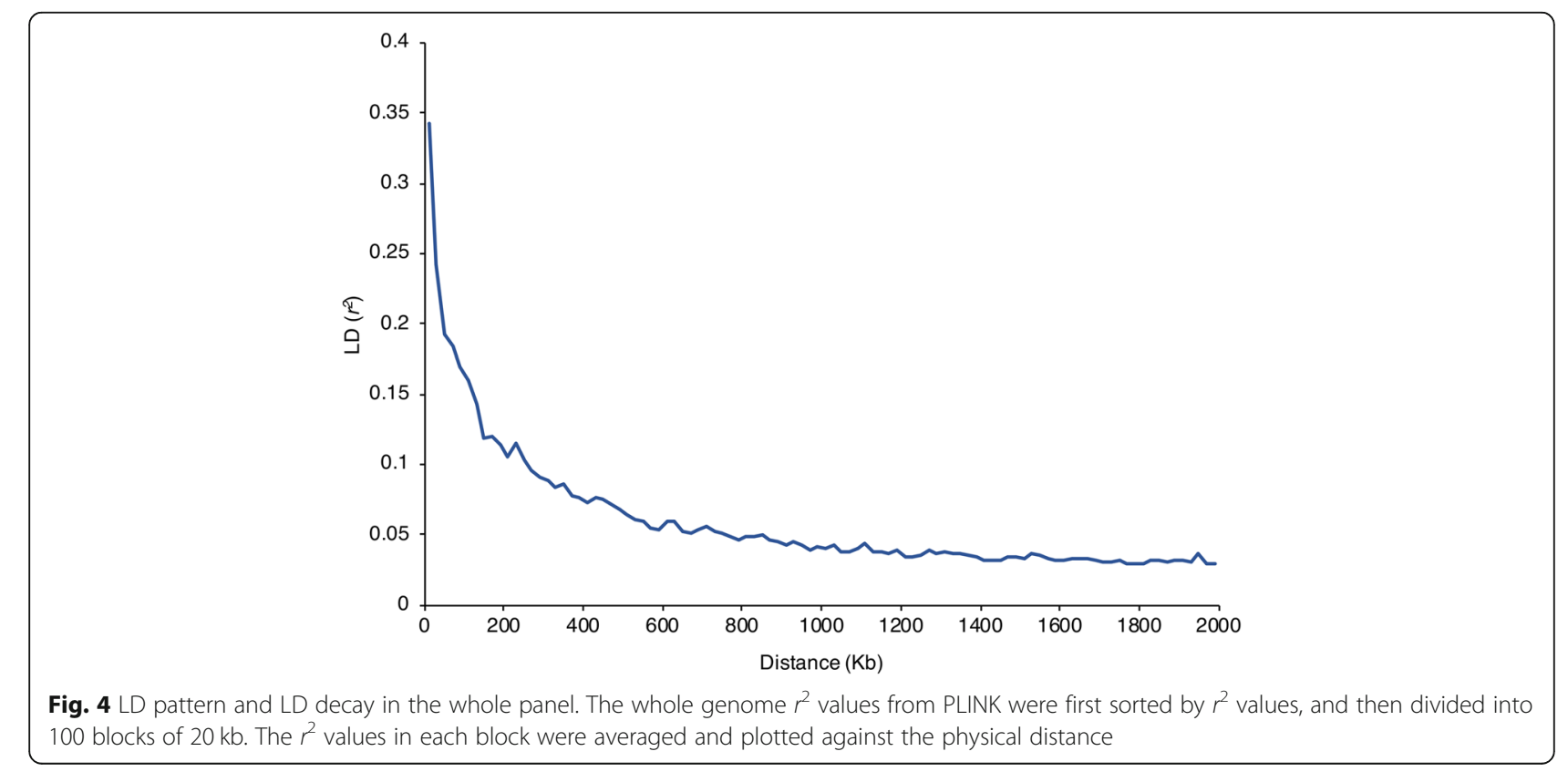


$P_{\mathrm{N}}$ day6

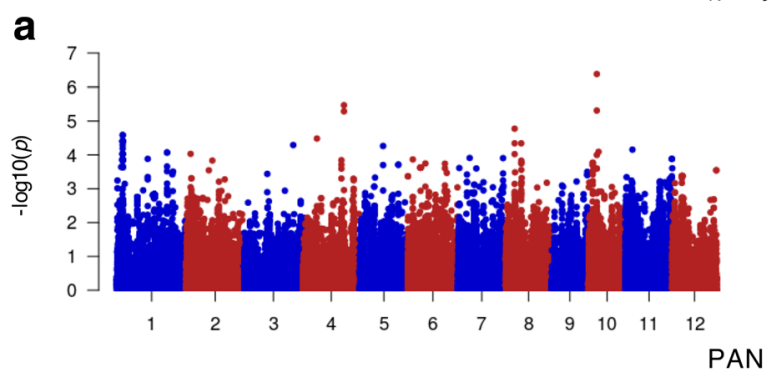

b

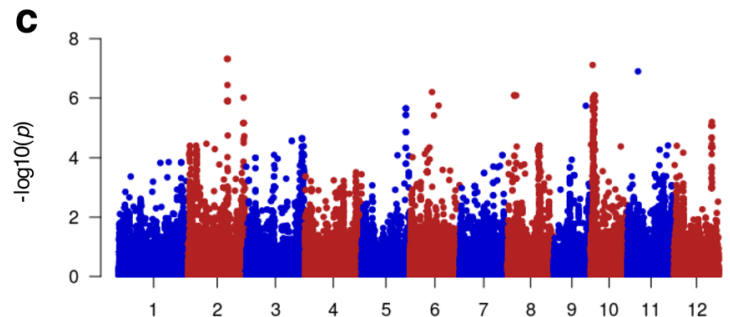

d
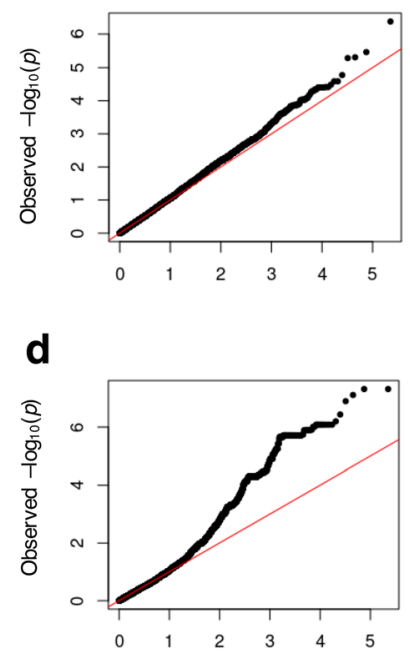

FG
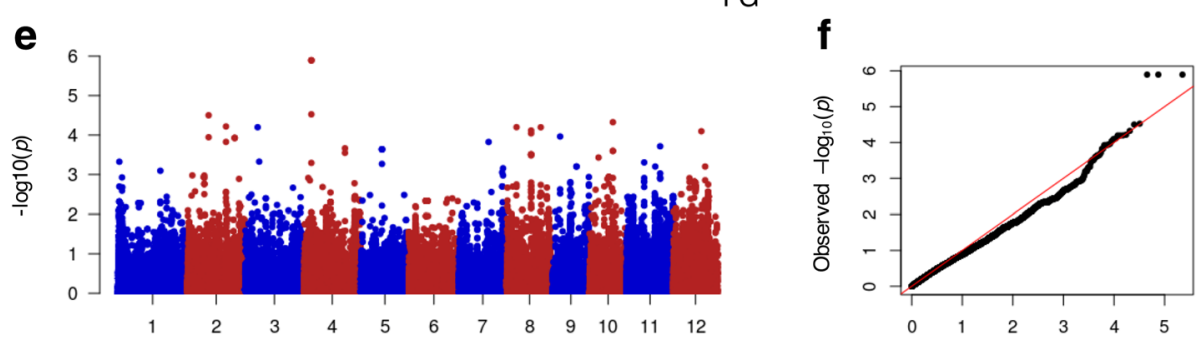

UFG
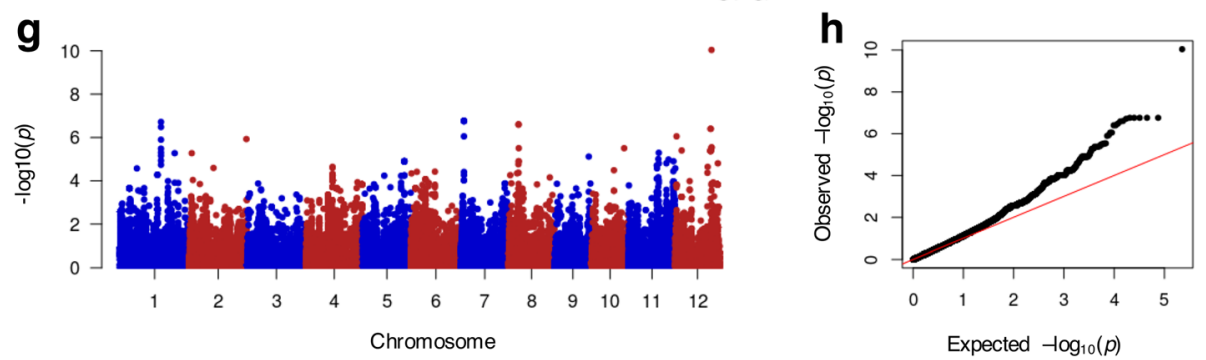

Fig. 5 Manhattan and Quantile-quantile (Q-Q) plots of GWAS. GWAS analysis was carried out using SNP markers from the exon region associated with (a and $\mathbf{b}$ ) $P_{\mathrm{N}}$ on day 6 after the salt stress treatment: $P_{\mathrm{N}}$.day6 (c and $\mathbf{d}$ ) PAN (e and $\mathbf{f}$ ) FG ( $\mathbf{g}$ and $\mathbf{h}$ ) UFG of 104 accessions as phenotypic data. For Manhattan plots, $x$-axis represents SNP positions across the entire rice genome by chromosome and the $y$-axis is the negative logarithm $p$-value: $-\log _{10}(p)$ of each SNP. For Q-Q plots, $x$-axis represents expected $-\log _{10}(p)$ and $y$-axis is observed $-\log _{10}(p)$ of each SNPS. $P_{N}$ : net photosynthetic rate; $g_{\mathrm{s}}$ : stomatal conductance; $E$ : transpiration rate; $C_{\mathrm{i}}$ : intercellular $\mathrm{CO}_{2}$ concentration; $\mathrm{CMS}$ : cell membrane stability, TIL: number of tillers per plant; PAN: number of panicles per plant; FG: number of filled grains per plant and UFG: number of unfilled grains per plant

of the significant SNPs (33 SNPs) was located in qGY12.1 (RM519-RM1103) on chromosome 12, which associated with grain yield (GY) of rice under salt stress at reproductive stage. On chromosome 3, 28 significant SNPs were located in qGP3 (RM49-RM6712), which involved germination percentage (GP) of rice under salt stress [57]. This region was overlapped with 2 QTLs, including $q$ PL3.1 $s \quad$ (RM520-RM570) and qSHL-3 (RM7000-RM7389). These QTLs were correlated with the panicle length (PL) and shoot length (SHL) [56, 58]. Finally, for salt-treated
QTLs of rice involving day of seedling survival (DSS) on chromosome 2, we found that qDSS2.1 (RM109-RM110) containing 19 significant SNPs identified in this study.

\section{Discussion}

Variations of the salt tolerance of rice at the flowering stage

Salt-tolerance of rice is a dynamic trait affected by growing stage and genotype [59,60]. This study is the first large-scale tolerance evaluation and GWAS focusing on 
Table 2 List of genes identified by GWAS that contained multiple neighboring significant SNPs and/or significant SNPs of low $p$-value

\begin{tabular}{|c|c|c|c|c|}
\hline Trait & Chr & SNP & Loc Number & Description \\
\hline$P_{\mathrm{N} \text {. day6 }}$ & 10 & 1 & LOC_Os10g09700 & OsWAK110 receptor-like kinase \\
\hline \multirow[t]{28}{*}{ PAN } & \multirow[t]{6}{*}{2} & 3 & LOC_Os02g40410 & expressed protein \\
\hline & & 4 & LOC_Os02g40420 & expressed protein \\
\hline & & 1 & LOC_Os02g55910 & monogalactosyldiacylglycerol synthase \\
\hline & & 4 & LOC_Os02g56020 & methyltransferase \\
\hline & & 1 & LOC_Os02g56130 & PCNA - Putative DNA replicative polymerase clamp \\
\hline & & 1 & LOC_Os02g56630 & OsWAK24 - OsWAK receptor-like protein \\
\hline & \multirow[t]{5}{*}{5} & 1 & LOC_Os05g47670 & zinc finger, $\mathrm{C} 3 \mathrm{HC} 4$ \\
\hline & & 2 & LOC_Os05g47690 & reticulon domain containing protein \\
\hline & & 1 & LOC_Os05g47770 & serine/threonine-protein kinase At1g18390 precursor \\
\hline & & 1 & LOC_Os05g47780 & E3 ubiquitin ligase \\
\hline & & 4 & LOC_Os05g47790 & expressed protein \\
\hline & \multirow[t]{17}{*}{10} & 1 & LOC_Os10g03620 & OsFBX344 - F-box domain containing protein \\
\hline & & 36 & LOC_Os10g03660 & OsFBX345 - F-box domain containing protein \\
\hline & & 20 & LOC_Os10g03669 & expressed protein \\
\hline & & 2 & LOC_Os10g03730 & OsFBX347 - F-box domain containing protein \\
\hline & & 2 & LOC_Os10g03740 & OsFBX348 - F-box domain containing protein \\
\hline & & 3 & LOC_Os10g03770 & expressed protein \\
\hline & & 3 & LOC_Os10g03780 & OsFBX351 - F-box domain containing protein \\
\hline & & 1 & LOC_Os10g04470 & conserved hypothetical protein \\
\hline & & 2 & LOC_Os10g04480 & expressed protein \\
\hline & & 25 & LOC_Os10g04490 & expressed protein \\
\hline & & 3 & LOC_Os10g04510 & expressed protein \\
\hline & & 2 & LOC_Os10g04520 & expressed protein \\
\hline & & 1 & LOC_Os10g04560 & hypothetical protein \\
\hline & & 3 & LOC_Os10g05050 & expressed protein \\
\hline & & 6 & LOC_Os10g05160 & expressed protein \\
\hline & & 2 & LOC_Os10g05170 & OsWAK100 receptor-like kinase \\
\hline & & 1 & LOC_Os10g05180 & $26 \mathrm{~S}$ proteasome regulatory subunit S5A \\
\hline FG & 4 & 3 & LOC_Os04g08749 & expressed protein \\
\hline \multirow[t]{9}{*}{ UFG } & 1 & 8 & LOC_Os01g45120 & expressed protein \\
\hline & \multirow[t]{4}{*}{7} & 2 & LOC_Os07g04220 & $\begin{array}{l}\text { wound and phytochrome signaling involved } \\
\text { receptor like kinase }\end{array}$ \\
\hline & & 2 & LOC_Os07g04270 & hypothetical protein \\
\hline & & 1 & LOC_Os07g04290 & alcohol oxidase-related protein \\
\hline & & 1 & LOC_Os07g04310 & expressed protein \\
\hline & \multirow[t]{3}{*}{8} & 1 & LOC_Os08g 10330 & SHR5-receptor-like kinase \\
\hline & & 1 & LOC_Os08g 10430 & NBS-LRR disease resistance protein \\
\hline & & 1 & LOC_Os08g10440 & NBS-LRR disease resistance protein \\
\hline & 12 & 1 & LOC_Os12g36630 & universal stress protein domain containing protein \\
\hline
\end{tabular}

salt stress at the reproductive stage of rice [61]. In this study, we applied salt stress to flowering rice and evaluated five parameters of photosynthetic performance (photosynthetic rate, $P_{\mathrm{N}}$; stomatal conductance, $g_{\mathrm{s}}$; transpiration rate,
$E$; and intercellular $\mathrm{CO}_{2}$ concentration, $C_{\mathrm{i}}$ ), cell membrane stability, CMS and four parameters of yield-related traits (number of tillers per plant, TIL; number of panicles per plant, PAN; number of filled grains per plant, FG; and 


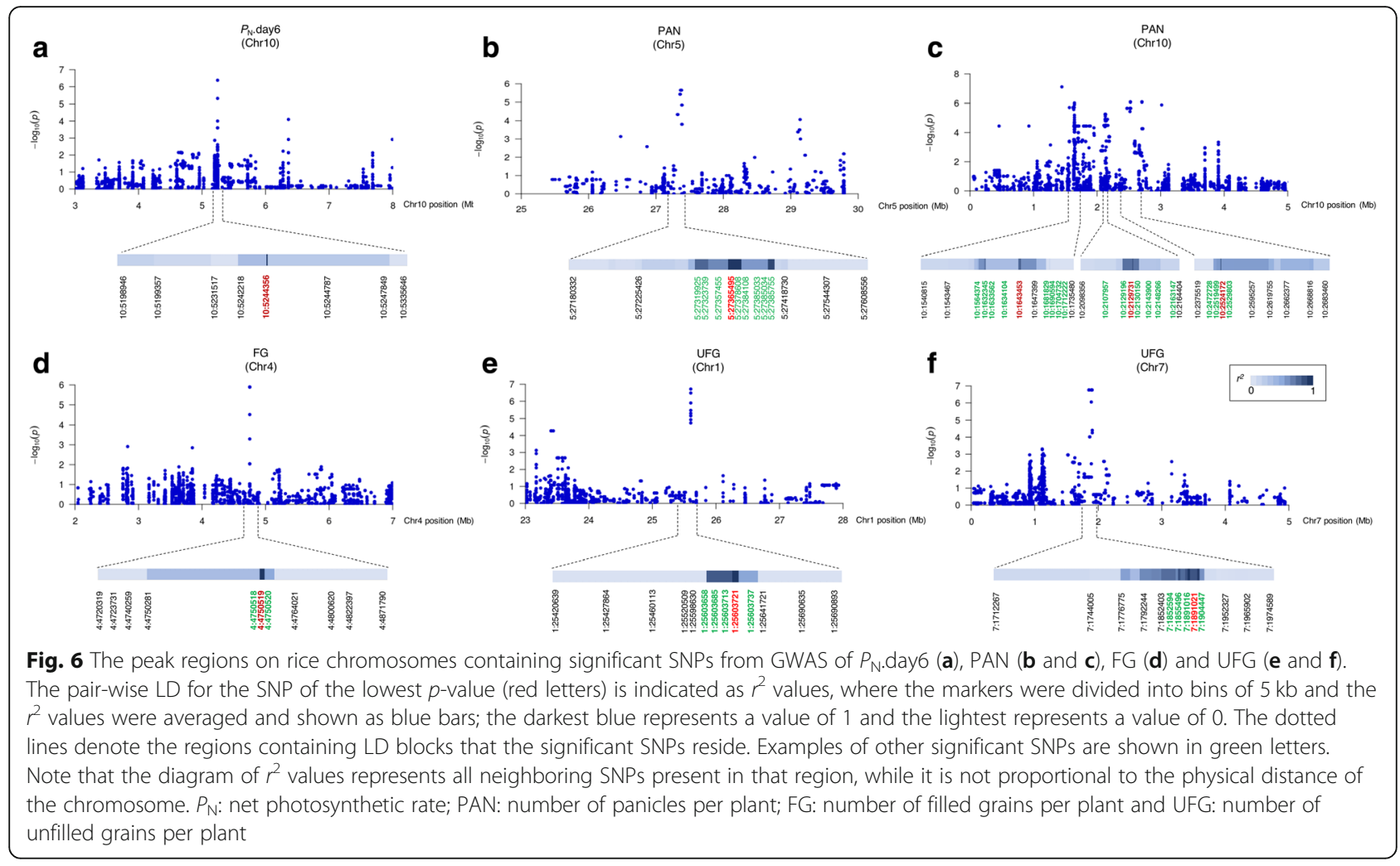

number of unfilled grains per plant, UFG). On average, the stability indices of photosynthesis performance and CMS decreased under salt stress, while increases of $C_{\mathrm{i}}$ were found, which were similar to the yield parameter, UFG (Table 1 and Fig. 1). For $P_{\mathrm{N}}, E$ and $g_{s}$, these findings agreed with previous studies describing salt-induced photosynthesis reduction in rice seedlings [62-64]. Consistently, during the reproductive stage, Moradi and Ismail [65] found that $P_{\mathrm{N}}, E$ and $g_{s}$ were inhibited in the flag leaf under salinity. Additionally, the salt-sensitive rice cultivar IR29 displayed higher $C_{i}$ than others when exposed to salt stress during both seedling and reproductive stages. As indicated by Burghardt et al. [27], GWAS would have power to discover genes affecting the trait of interest in large of phenotypic variation greater than small of phenotypic variation. In this study, large variation was observed in $P_{\mathrm{N}}$ in photosynthesis performance; and PAN, FG and UFG in yield-related traits under salt stress (Fig. 1). Correspondingly we found high detection power of association mapping in these parameters, whereas GWAS for the other parameters that exhibited lower variation was not successful (Fig. 5).

\section{Rice genome variations and genome-wide association mapping}

Using efficient, high precision exome capture and sequencing, we have identified 112,565 SNPs. Previous studies used SNP array to identify SNP markers for GWAS in rice and yielded fewer SNP markers when compared with our study [33, 38, 66]. The present study, however, focused on exonic regions, which are specific sequences in the genome while accounting for only one-sixth of the rice genome, resulted in more than 100,000 SNPs. Although several statistically robust models have been developed for GWAS [67], population structure can limit its effectiveness $[68,69]$. Our Thai rice population belongs to the indica group (Additional file 5: Figure S2). While its size is relatively small compared human studies, GWAS with similar population size has been effective in Arabidopsis [24] and rice [26]. Indeed, diversified composition of our population, lack of strong subpopulation structure, and its homozygosity facilitated GWAS [26, 38].

\section{Candidate genes associated with salt tolerance of rice at the flowering stage}

Altogether, GWAS using this Thai rice population leveraged more than 110,000 SNPs to identify 448 SNPs associated with salt tolerance, which were located in 200 loci in the rice genome. As presented in Table 3, 73\% of candidate genes from association mapping associated with salt stress were located within salinity tolerance QTLs identified in bi-parental segregating populations.

Functional annotation of the 200 identified genes revealed a number of plausible candidates. The gene annotations we employed relay on the presence of a protein domain or of a homolog with a known function 


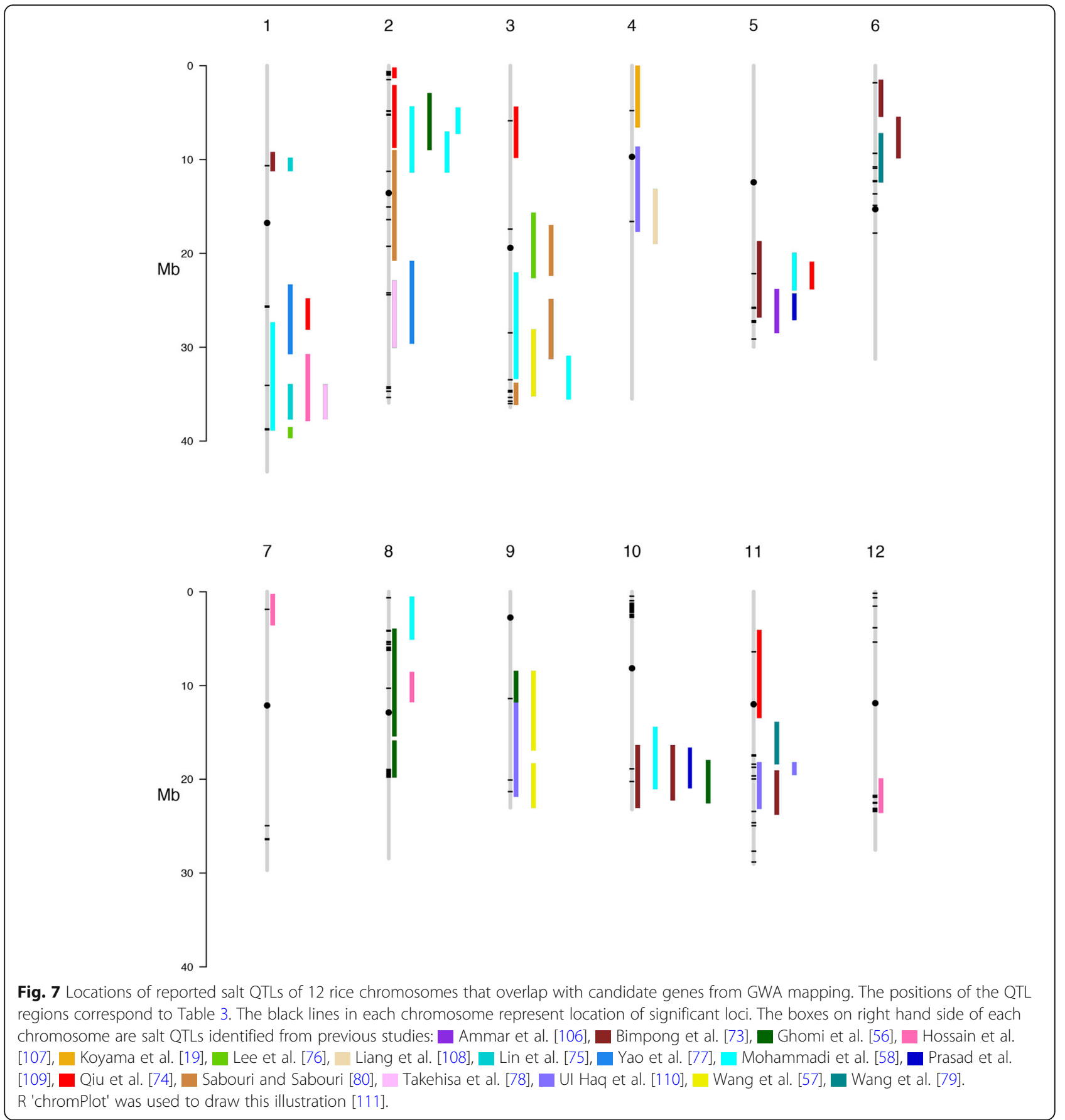

in rice and other crop species such as maize or sorghum [70, 71], as well as Arabidopsis [72]. Two chromosomes contained the highest number of reported salt QTLs (Table 3 and Fig. 7) overlapping with 7 of our candidate loci: chromosome 1, which included 16 QTLs [58, 73-78, 107] and chromosome 2, which included 10 QTLs [56, 58, $74,77,79,80]$. The nature of the candidate genes indicates that different molecular and cellular strategies have evolved to favor survival during salt stress [81]. Several genes belong to the receptor kinase family
(LOC_Os01g66740, LOC_Os01g66760, LOC_Os02g02120 and LOC_Os02g56630), encoding signaling factors during environmental stresses [82, 83]. LOC_Os01g18850, one of candidate genes detected by GWA mapping of UFG trait, encodes SQUAMOSA promoter binding protein-like (SPL) transcription factor (TF), a plant specific TF, whose function was suggested to affect a broad range growth and development processes, including flower development [84] and 19 SPL genes were identified in rice [85]. The role of SPL gene in salt stress response has been studied 
$\begin{array}{ll}\text { Lekklar et al. BMC Genomics } & \text { (2019) 20:76 }\end{array}$

Page 12 of 18

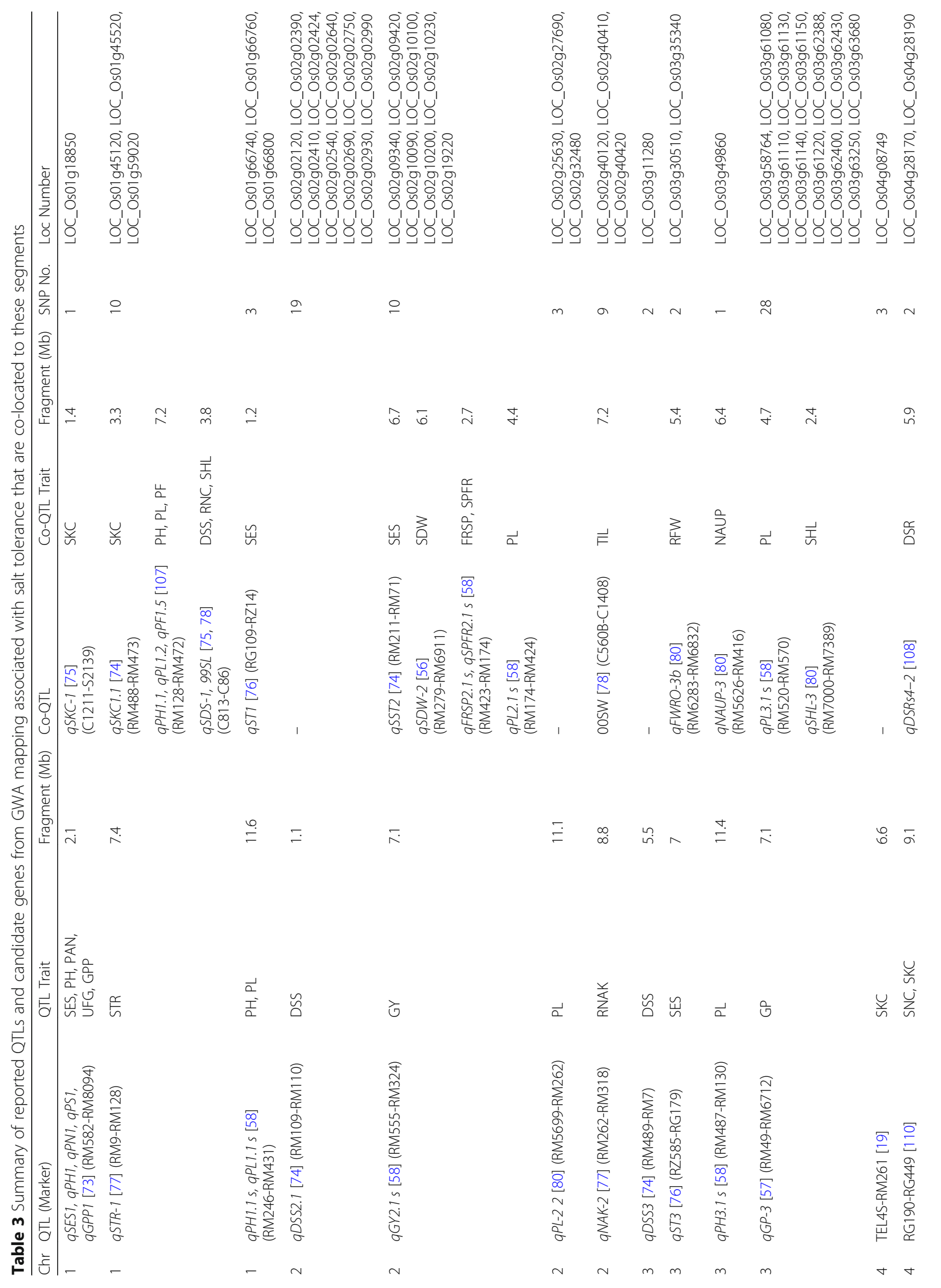


Lekklar et al. BMC Genomics

(2019) 20:76

Page 13 of 18

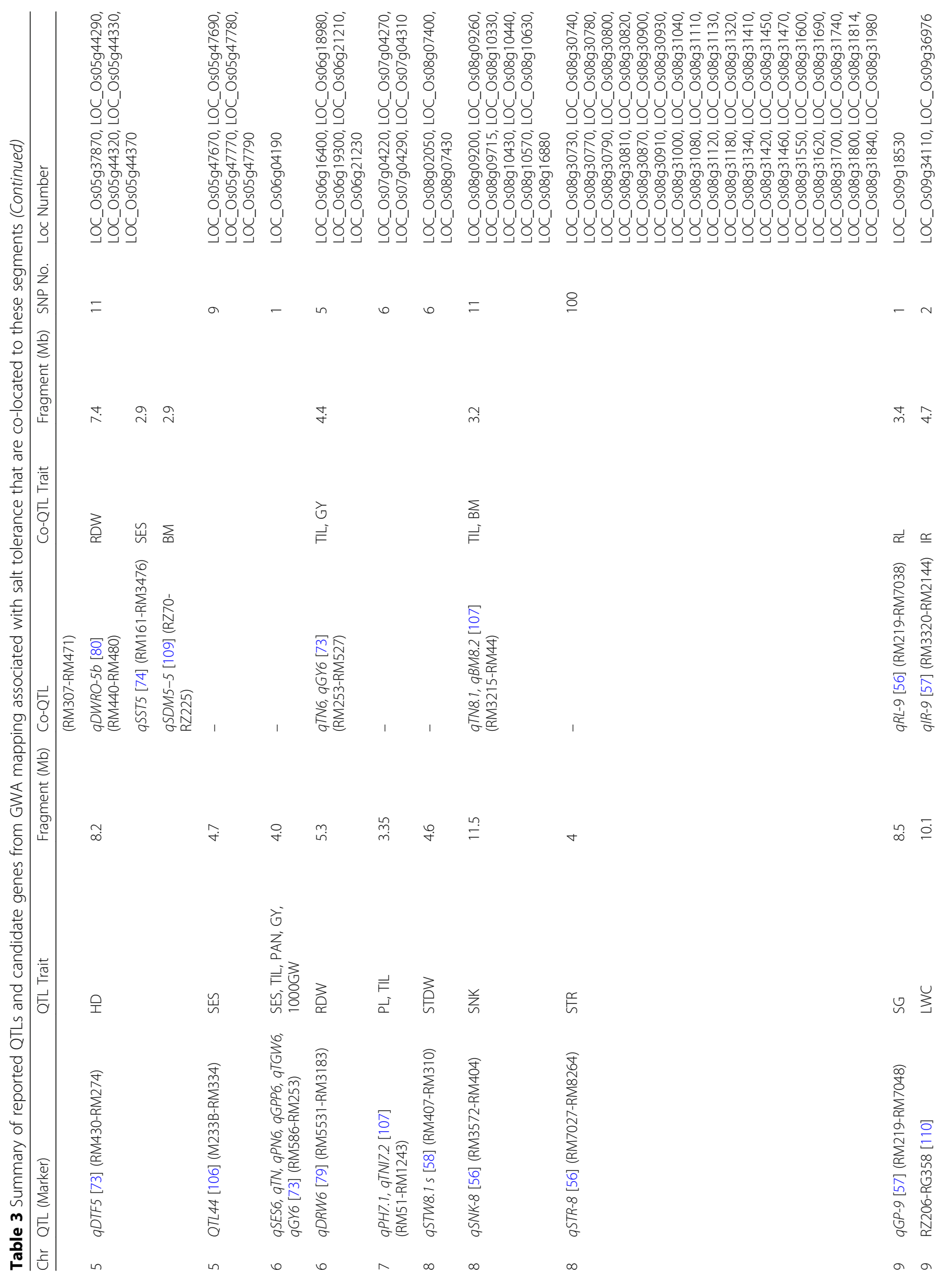




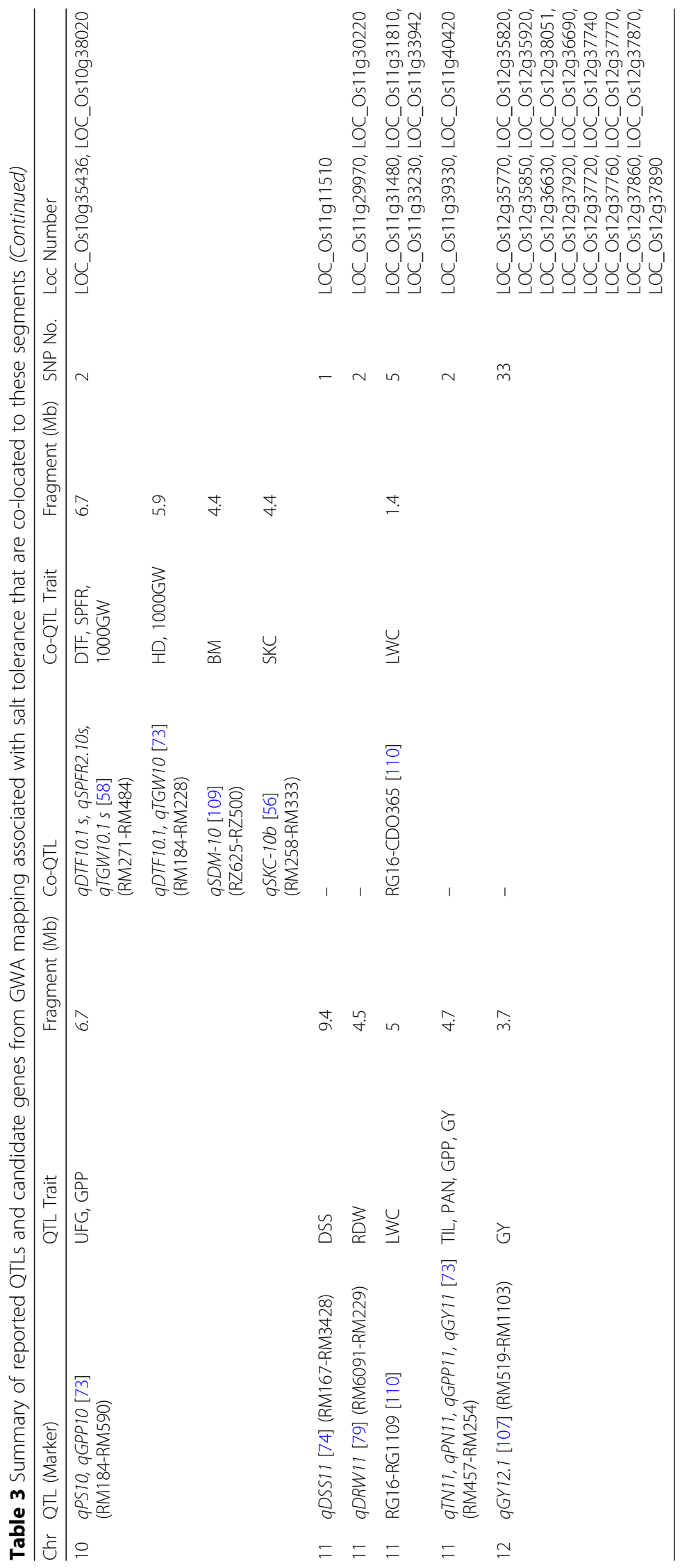


by Mao et al. [86]. The 31 SPL genes were identified in maize and the expression profiles of SPLS revealed that most SPL genes were induced under salt stress condition.

A candidate gene identified here encodes cytochrome P450 monooxygenases (LOC_Os01g59020). This enzyme, common to bacteria, plants and humans, shares a common catalytic center, a heme with an iron coordinated to the thiolate of a conserved cysteine [87]. They oxidize disparate substrates through activation of molecular oxygen. The plant P450 gene superfamily plays crucial roles in plant metabolic processes [88]. Narusaka et al. [89] analyzed the expression of 49 Arabidopsis P450 genes under various stresses, including salt stress, and found that 29 P450genes were induced by various stresses. In the CYP709B subfamily of P450, a cyp709b3 Arabidopsis mutant showed sensitivity to salt stress during germination and high salt-damage at the seedling stage [90]. In rice, Tamiru et al. [91] reported that a P450 gene, OsDSS1 located on chromosome 3 was involved in growth and drought stress responses. Compared to WT, the $d s s 1$ rice mutant exhibited improved recovery after germination under drought stress. Additionally, ectopic expression of the P450 gene PtCYP714A3 from Populus trichocarpa was studied in rice. Transgenic rice expressing PtCYP714A3 was semidwarf with improved tolerance to salt and osmotic stress, resulting in higher survival rates than WT [92].

Interestingly, several novel candidate loci with 144 significant SNPs identified from this GWA mapping were found on chromosome 10, in which no salt QTL was reported. This represents the highest density of significant SNPs found in the same LD block (Fig. 6c). Interestingly, seven of these SNP-associated genes encoded F-box domain containing proteins (LOC_Os10g03620, LOC_ Os10g03660, LOC_Os10g03730, LOC_Os10g03740, LOC_ Os10g03780, LOC_Os10g03930 and LOC_Os10g05500). Previous studies have reported the role of F-box proteins in regulating various abiotic stress responses in Arabidopsis, wheat and rice [93-97]. A conserved N-terminal F-box domain (40-50 amino acids), is a component of the multi-subunit of ubiquitin E3 ligase, an enzyme in the last step of the ubiquitination pathway $[98,99]$. The rice genome harbors more than 600 F-box genes whose divergence is consistent with adaptive roles [100] and regulation of 25 of these genes responds to salinity stress [94]. Rice seedlings overexpressing F-box protein gene, MAIF1 reduced inhibition of root growth and tolerance under salt stress compared with WT [97]. Salt induced the expression of $O s M s r 9$, a novel rice putative F-box containing protein, especially in the panicle. Overexpression of OsMsr9 increased root length, shoot length and survival rate under salt stress [101].

Moreover, SNP with the lowest $p$-value $\left(9.04 \times 10^{-11}\right)$ found on chromosome 12 of GWA mapping of UFG (Table 2, Additional file 7: Figure S3d) was located in
LOC_Os12g36630, which was annotated as a universal stress protein (USP) domain containing protein. In fact, USP genes are widely distributed across many organisms including plant, which encode a protein containing the 140-160 highly conserved residues of the Universal Stress Protein A domain (USPA, Pfam accession number PF00582). These genes were reported as environmental stress-responsive genes and played role in the ability of plant to respond to the stresses [102, 103]. To date, there are no report on the role of USP genes in salt-treated rice. However, in the study on OsUsp1 in rice under oxygen deficiency condition, it was found that OsUsp1 expression was strongly induced within $1 \mathrm{~h}$ of submergence and it played a role in ethylene-mediated stress adaptation in rice [104]. Furthermore, the role of the USP protein (At3g53990: AtUsp) in enhancing oxidative stress has been reported in the plant model Arabidopsis [105]. They found that the over-expression of AtUSP conferred a strong tolerance to oxidative stress, primarily via its chaperone function.

\section{Conclusion}

High quality genotyping data from high-throughput sequencing combined with robust statistical analysis, enables GWA mapping of complex quantitative traits. We conducted GWAS for salt tolerance during rice reproduction based on high-density SNPs in exon regions using indica Thai accessions. Altogether, the significant SNPs were located on 200 loci distributed among all rice chromosomes. Our GWA mapping was highly consistent with previous salt tolerance QTL mapping studies conducted in bi-parental populations. Overall, more than $73 \%$ of the candidate genes controlling salt tolerance identified in our GWAS overlap with the salt QTLs. While many are novel, their annotation is consistent with potential involvement in plant salt tolerance and in related agronomic traits. These significant SNPs greatly help narrow down the region within these QTLs where the likely underlying candidate genes can be identified. Knowledge on the varieties with high salt tolerance, as well as the associated SNPs from this study, will be useful for future improvement of rice yield productivity under salt stress.

\section{Additional files}

Additional file 1: Table S1. List of all rice accessions used for SNP genotyping. Rice accessions are tabled with their geographical locations, GS No., parental lines/parental relations and heterozygosity. (XLSX 19 kb)

Additional file 2: Table S2. List of rice accessions and phenotypic data used for association mapping. The average values of four biological replicates are shown. (XLSX $50 \mathrm{~kb}$ )

Additional file 3: Figure S1. Frequency distribution of $P_{\mathrm{N}}$ : net photosynthetic rate; $g_{\mathrm{s}}$ : stomatal conductance; $E$ : transpiration rate; $C_{\mathrm{i}}$ : intercellular $\mathrm{CO}_{2}$ concentration, CMS: cell membrane stability, TIL: number of tillers per plant; PAN: number of panicles per plant; FG: number of 
filled grains per plant and UFG: number of unfilled grains per plant for 104 rice accessions under control ( $a$ and $b$ ) and salt stress conditions (c and d). (PDF $306 \mathrm{~kb}$ )

Additional file 4: Table S3. Pearson's correlation coefficients of the phenotypic traits measured in 104 rice accessions. Data are from salt susceptible indices of each trait. Shaded values are significant at $p<0.05, p<0.01$, or $p<0.001$, darker shading indicates higher significance. (XLSX $11 \mathrm{~kb}$ )

Additional file 5: Figure S2. Population structure of 190 rice association panels, which consisted mostly of the indica accessions. (TIF $5827 \mathrm{~kb}$ )

Additional file 6: Table S4. List of significant SNPs from GWA mapping for various traits under control and stress conditions using compressed MLM. Details are also given for MSU Locus ID and their putative functions from where the respective SNP was selected. (XLSX $39 \mathrm{~kb}$ )

Additional file 7: Figure S3. The peak regions on rice chromosomes containing significant SNPs from GWAS of PAN ( $a$ and $b$ ) and UFG (c and d). The pair-wise LD for the SNP of the lowest p-value (red letters) is indicated as $\mathrm{r} 2$ values, where the markers were divided into binds of $5 \mathrm{~kb}$ and the $r 2$ values were averaged and shown as blue bars; the darkest blue represents a value of 1 and the lightest blue represents a value of 0 . The dotted lines denote the regions containing LD blocks that the significant SNPs reside. Examples of other significant SNPs are shown in green letters. Note that the diagram of $\mathrm{r} 2$ values represents all neighboring SNPs present in that region, while it is not proportional to the physical distance of the chromosome. (TIFF $9604 \mathrm{~kb}$ )

\section{Abbreviations}

1000GW: 1000-grain weight; BM: Biomass; $\mathrm{C}_{\mathrm{i}}$ : Intercellular $\mathrm{CO}_{2}$ concentration; CMS: Cell membrane stability; DAT: Day after treatment; DSR: Dead seedling rate; DSS: Days of seedling survival; DTF: Day to flower; E: Transpiration rate; EC: Electrical conductivity; FG: Number of filled grains per plant; FRSP: Number of fertile spikelets; GP: Germination Percentage; GPP: Grains per panicle; $g_{s}$ : Stomatal conductance; GWAS: Genome-wide association study; GY: Grain yield; HD: Heading date; IR: Imbibition rate; LD: Linkage Disequilibrium; LWC: Leaf water content; MAF: Minor allele frequency; MLM: Mixed linear model; NAUP: $\mathrm{Na}^{+}$uptake; PAN: Number of panicles per plant; PF: Pollen fertility; PH: Plant height; PL: Plant length; $P_{N}$ : Net photosynthetic rate; Q-Q: The quantile-quantile; QTLs: Quantitative trait loci; RDW: Root dry weight; RFW: Root fresh weight; RL: Root length; RNAK: Root $\mathrm{Na}^{+} / \mathrm{K}^{+}$ratio; RNC: Root $\mathrm{Na}^{+}$concentration; SDW: Shoot dry weight; SES: Salt evaluation score; SHL: Shoot length; SKC: Shoot $\mathrm{K}^{+}$concentration; SNC: Shoot $\mathrm{Na}^{+}$concentration; SNK: Shoot $\mathrm{Na}^{+} / \mathrm{K}^{+}$ratio; SNP: Single nucleotide polymorphism; SPFR: Spikelet fertility; STDW: Straw dry weight; STR: Standard tolerance ranking; TIL: Number of tillers per plant; UFG: Number of unfilled grains per plant

\section{Acknowledgements}

We thank Dr. Somsong Chotechuen, Pathum Thani Rice Research Center, Rice Department, Ministry of Agriculture and Cooperatives for kind advice; Ms. Isabelle Henry and Mr. Meric Lieberman in Luca Comai's laboratory; and Ms. Thammaporn Kojonna, Mr. Nopphakhun Khunpolwattana, Ms. Nattaya Tantipirom and Mr. Worawat Yuenyong, students under CE in Environment and Plant Physiology, Department of Botany, Faculty of Science,

Chulalongkorn University, for technical support.

\section{Funding}

This work was supported by a grant from Nation Research Council of Thailand and the Agricultural Research Development Agency (2555NRCT512302): Omics sciences for salt tolerant studies in Thai rice (Oryza sativa L.). $\mathrm{CL}$ was supported by the 100th Anniversary Chulalongkorn University Fund for Doctoral Scholarship and an Overseas Research Experience Scholarship for Graduate Student, Graduate School, Chulalongkorn University.

\section{Availability of data and materials}

All genome sequencing raw data and the code used to execute the GWAS are available through direct contact.

\section{Authors' contributions}

$\mathrm{CL}$ carried out the laboratory work along with $\mathrm{AC}, \mathrm{HT}$ and $\mathrm{DS}$; and prepared figures and Tables. MP, SC and TB participated in database searches and data analyses. CL, SC, LC and TB performed data interpretation and drafted the manuscript. All authors read and approved the final manuscript.

\section{Ethics approval and consent to participate}

The rice material (Accession number: 190) used in this study was obtained from the Pathum Thani Rice Research Center, Rice Department, Ministry of Agriculture and Cooperatives, Thailand (http://ptt-rrc.ricethailand.go.th/ index.php), and is publicly available for non-commercial purposes.

\section{Consent for publication}

Not applicable.

\section{Competing interests}

The authors declare that they have no competing interests.

\section{Publisher's Note}

Springer Nature remains neutral with regard to jurisdictional claims in published maps and institutional affiliations.

\section{Author details}

${ }^{1}$ Biological Sciences Program, Faculty of Science, Chulalongkorn University, Bangkok, Thailand. ${ }^{2}$ Center of Excellent in Environment and Plant Physiology, Department of Botany, Faculty of Science, Chulalongkorn University, Bangkok, Thailand. ${ }^{3}$ Department of Mathematics and Computer Science, Faculty of Science, Chulalongkorn University, Bangkok, Thailand. ${ }^{4}$ Omics Sciences and Bioinformatics Center, Faculty of Science, Chulalongkorn University, Bangkok, Thailand. ${ }^{5}$ Nakhon Ratchasima Rice Research Center, Rice Department, Ministry of Agriculture and Cooperatives, Nakhon Ratchasima, Thailand. ${ }^{6}$ Department of Biochemistry, Faculty of Science, Chulalongkorn University, Bangkok, Thailand. 'DDepartment of Plant Biology and Genome Center, University of California Davis, Davis, CA, USA.

Received: 29 May 2018 Accepted: 27 November 2018

Published online: 22 January 2019

\section{References}

1. Munns R, Tester M. Mechanisms of salinity tolerance. Annu Rev Plant Biol. 2008:59:651-81.

2. Carillo P, Annunziata MG, Pontecorvo G, Fuggi A, Woodrow P. Salinity stress and salt tolerance. In: Shanker A, Venkateswarlu B, editors. Abiotic stress in plants - mechanisms and adaptations. Rijeka: InTech; 2011. p. 21-38.

3. Chaves MM, Flexas J, Pinheiro C. Photosynthesis under drought and salt stress: regulation mechanisms from whole plant to cell. Ann Bot. 2009;103: 551-60

4. Parida AK, Das AB. Salt tolerance and salinity effects on plants: a review. Ecotoxicol Envi Safety. 2005:60:324-49.

5. Deinlein U, Stephan AB, Horie T, Luo W, Xu G, Schroeder Jl. Plant salttolerance mechanisms. Trends Plant Sci. 2014;19:371-9.

6. Negrão S, Schmöckel SM, Tester M. Evaluating physiological responses of plants to salinity stress. Ann Bot. 2017;119:1-11.

7. Ismail A, Takeda S, Nick P. Life and death under salt stress: same players, different timing? J Exp Bot. 2014;65:2963-79.

8. Hussain M, Ahmad S, Hussain S, Lal R, UI-Allah S, Nawaz A. Chapter Six Rice in saline soils: physiology, biochemistry, genetics, and management. In: Sparks DL, editor. Advances in agronomy. Academic press; 2018. p. 231-87.

9. Bibha R, Sharma VK. Standarization of mathodology for obtaining the desired salt stress environment for salinity effect observation in rice seedlings. Int J Environ Sci. 2015;6:232-6.

10. Mass EV, Hoffman GJ. Crop Salt Tolerance-Current Assessment, vol. 103. p. 1977.

11. Flowers TJ. Improving crop salt tolerance. J Exp Bot. 2004;55:307-19.

12. Li ZK, Xu JL. Breeding for drought and salt tolerant rice (Oryza Sativa L.): progress and perspectives. In: Jenks MA, Hasegawa PM, Jain SM, editors. Advances in molecular breeding toward drought and salt tolerant crops. Dordrecht: Springer; 2007. p. 531-64.

13. Takeda S, Matsuoka M. Genetic approaches to crop improvement: responding to environmental and population changes. Nat Rev Genet. 2008;9:444. 
14. Zhu JK. Genetic analysis of plant salt tolerance using Arabidopsis. Plant Physiol. 2000;124:941-8.

15. Wu JL, Wu C, Lei C, Baraoidan M, Bordeos A, Madamba MRS, RamosPamplona M, Mauleon R, Portugal A, Ulat VJ, et al. Chemical- and irradiation-induced mutants of indica rice IR64 for forward and reverse genetics. Plant Mol Biol. 2005;59:85-97.

16. Jiang Y, Cai Z, Xie W, Long T, Yu H, Zhang Q. Rice functional genomics research: Progress and implications for crop genetic improvement. Biotechnol Adv. 2012;30:1059-70.

17. Ellis RP, Forster BP, Gordon DC, Handley LL, Keith RP, Lawrence P, Meyer R, Powell W, Robinson D, Scrimgeour CM, et al. Phenotype/genotype associations for yield and salt tolerance in a barley mapping population segregating for two dwarfing genes. J Exp Bot. 2002;53:1163-76.

18. Lee G, Carrow RN, Duncan RR. Photosynthetic responses to salinity stress of halophytic seashore paspalum ecotypes. Plant Sci. 2004;166:1417-25.

19. Koyama ML, Levesley A, Koebner RM, Flowers TJ, Yeo AR. Quantitative trait loci for component physiological traits determining salt tolerance in rice. Plant Physiol. 2001;125:406-22.

20. Balasubramanian S, Schwartz C, Singh A, Warthmann N, Kim MC, Maloof JN Loudet O, Trainer GT, Dabi T, Borevitz JO, et al. QTL mapping in new Arabidopsis thaliana advanced intercross-recombinant inbred lines. PLoS One. 2009:4:e4318.

21. Flint-Garcia SA, Thornsberry JM, IV ESB. Structure of linkage disequilibrium in plants. Annu Rev Plant Biol. 2003;54:357-74.

22. Huang $X$, Han B. Natural variations and genome-wide association studies in crop plants. Annu Rev Plant Biol. 2014;65:531-51.

23. Guo L, Gao Z, Qian Q. Application of resequencing to rice genomics, functional genomics and evolutionary analysis. Rice. 2014;7:4.

24. Atwell S, Huang YS, Vilhjálmsson BJ, Willems G, Horton M, Li Y, Meng D, Platt A, Tarone AM, Hu TT, et al. Genome-wide association study of 107 phenotypes in Arabidopsis thaliana inbred lines. Nature. 2010;465:627.

25. Brachi B, Morris GP, Borevitz JO. Genome-wide association studies in plants: the missing heritability is in the field. Genome Biol. 2011;12:232.

26. Ff X, Ff T, Yf S, YI C, Tong C, Js B. Genotype $\times$ environment interactions for agronomic traits of rice revealed by association mapping. Rice Sci. 2014;21: 133-41.

27. Burghardt LT, Young ND. Tiffin P. a guide to genome-wide association mapping in plants. Curr Protoc. Plant Biol. 2017;2:22-38.

28. Huang X, Wei X, Sang T, Zhao Q, Feng Q, Zhao Y, Li C, Zhu C, Lu T, Zhang $Z$, et al. Genome-wide association studies of 14 agronomic traits in rice landraces. Nat Genet. 2010;42:961

29. Huang X, Zhao Y, Wei X, Li C, Wang A, Zhao Q. Genome-wide association study of flowering time and grain yield traits in a worldwide collection of rice germplasm. Nat Genet. 2012;44:32-9.

30. Wang Q, Xie W, Xing H, Yan J, Meng X, Li X, Fu X, Xu J, Lian X, Yu S, et al. Genetic architecture of natural variation in rice chlorophyll content revealed by a genome-wide association study. Mol Plant. 2015;8:946-57.

31. Kikuchi S, Bheemanahalli R, Jagadish KS, Kumagai E, Masuya $Y$, Kuroda E, Raghavan C, Dingkuhn M, Abe A, Shimono H. Genome-wide association mapping for phenotypic plasticity in rice. Plant Cell Environ. 2017:40:1565-75.

32. Famoso AN, Zhao K, Clark RT, Tung CW, Wright MH, Bustamante C, Kochian LV, McCouch SR. Genetic architecture of aluminum tolerance in rice (Oryza sativa) determined through genome-wide association analysis and QTL mapping. PLoS Genet. 2011;7:e1002221.

33. de Abreu Neto JB, Hurtado-Perez MC, Wimmer MA, Frei M. Genetic factors underlying boron toxicity tolerance in rice: genome-wide association study and transcriptomic analysis. J Exp Bot. 2017:68:687-700.

34. Shakiba E, Edwards JD, Jodari F, Duke SE, Baldo AM, Korniliev P, McCouch SR, Eizenga GC. Genetic architecture of cold tolerance in rice (Oryza sativa) determined through high resolution genome-wide analysis. PLoS One 2017;12:e0172133.

35. Kadam NN, Struik PC, Rebolledo MC, Yin X, Jagadish SVK. Genome-wide association reveals novel genomic loci controlling rice grain yield and its component traits under water-deficit stress during the reproductive stage. J Exp Bot. 2018;69:4017-32.

36. Patishtan J, Hartley TN, Fonseca de Carvalho R, Maathuis FJM. Genome-wide association studies to identify rice salt-tolerance markers. Plant Cell Environ. 2017:41:970-82.

37. Shi Y, Gao L, Wu Z, Zhang X, Wang M, Zhang C, Zhang F, Zhou Y, Li Z. Genome-wide association study of salt tolerance at the seed germination stage in rice. BMC Plant Biol. 2017;17:92.
38. Kumar V, Singh A, Mithra SV, Krishnamurthy SL, Parida SK, Jain S. Genomewide association mapping of salinity tolerance in rice (Oryza sativa). DNA Res. 2015;22:133-45.

39. Chitrakon S, Somrith B. The development of Thai rice varieties. In: Lorlowhakarn S, editor. Science and technology with Thai rice. Thailand's national science and technology development agency; 2003. p. 29-76.

40. Vajrabhaya M, Vajrabhaya T. Somaclonal variation for salt tolerance in rice. In: Bajaj YPS, editor. Biotechnology in agriculture and forestry. Heidelberg: Springer-Verlag Berlin; 1991. p. 368-82.

41. Blum A, Ebercon A. Cell membrane stability as a measure of drought and heat tolerance in wheat. Crop Sci. 1981;21:43-7.

42. Taiyun W, Viliam S: R package "corrplot": Visualization of a Correlation. In.; 2017

43. Missirian V, Comai L, Filkov V. Statistical mutation calling from sequenced overlapping DNA pools in TILLING experiments. BMC Bioinformatics. 2011;12:287.

44. Li H, Handsaker B, Wysoker A, Fennell T, Ruan J, Homer N, Marth G, Abecasis G, Durbin R. The sequence alignment/map format and SAMtools. Bioinformatics. 2009;25:2078-9.

45. Li H, Durbin R. Fast and accurate short read alignment with burrows-wheeler transform. Bioinformatics. 2009:25:1754-60.

46. McKenna A, Hanna M, Banks E, Sivachenko A, Cibulskis K, Kernytsky A, Garimella K, Altshuler D, Gabriel S, Daly M, et al. The genome analysis toolkit: a MapReduce framework for analyzing next-generation DNA sequencing data. Genome Res. 2010;20:1297-303.

47. Patterson N, Price AL, Reich D. Population structure and eigenanalysis. PLoS Genet. 2006;2:e190.

48. Price AL, Patterson NJ, Plenge RM, Weinblatt ME, Shadick NA, Reich D. Principal components analysis corrects for stratification in genome-wide association studies. Nat Genet. 2006:38:904-9.

49. Purcell S, Neale B, Todd-Brown K, Thomas L, Ferreira MA, Bender D. PLINK: a tool set for whole-genome association and population-based linkage analyses. Am J Hum Genet. 2007:81:559-75.

50. Browning $B L$, Zhou Y, Browning SRA. One-penny imputed genome from next-generation reference panels. Am J Hum Genet. 2018;103:338-48.

51. Zhou X, Stephens M. Genome-wide efficient mixed-model analysis for association studies. Nat Genet. 2012:44:821-4.

52. Zhou X, Stephens M. Efficient multivariate linear mixed model algorithms for genome-wide association studies. Nat Methods. 2014;11:407-9.

53. Turner SD. qqman: an R package for visualizing GWAS results using Q-Q and manhattan plots bioRxiv; 2014. https://doi.org/10.1101/005165.

54. Hu S, Tao H, Qian Q, Guo L. Genetics and molecular breeding for salttolerance in rice. Rice Genomics Genet. 2012;3:39-49.

55. Ruiz M, Sempéré G, Hamelin C. Using TropGeneDB: a database containing data on molecular markers, QTLs, maps, genotypes, and phenotypes for tropical crops. In: van ADJ D, editor. Plant genomics databases: methods and protocols. New York, NY: Springer New York; 2017. p. 161-72.

56. Ghomi K, Rabiei B, Sabouri H, Sabouri A. Mapping QTLs for traits related to salinity tolerance at seedling stage of rice ( Oryza sativa L.): An agrigenomics study of an Iranian rice population, vol. 17; 2013

57. Wang Z, Wang J, Bao Y, Wu Y, Zhang H. Quantitative trait loci controlling rice seed germination under salt stress. Euphytica. 2011;178:297-307.

58. Mohammadi R, Mendioro MS, Diaz GQ, Gregorio GB, Singh RK. Mapping quantitative trait loci associated with yield and yield components under reproductive stage salinity stress in rice (Oryza sativa L.). J Genet. 2013; 92:433-43.

59. Wankhade SD, Cornejo MJ, Mateu-Andrés I, Sanz A. Morpho-physiological variations in response to $\mathrm{NaCl}$ stress during vegetative and reproductive development of rice. Acta Physiol Plant. 2013;35:323-33.

60. Reddy INBL, Kim BK, Yoon IS, Kim KH, Kwon TR. Salt tolerance in rice: focus on mechanisms and approaches. Rice Sci. 2017;24:123-44.

61. Todaka D, Nakashima K, Shinozaki K, Yamaguchi-Shinozaki K. Toward understanding transcriptional regulatory networks in abiotic stress responses and tolerance in rice. Rice. 2012:5:6.

62. Nounjan N, Siangliw JL, Toojinda T, Chadchawan S, Theerakulpisut P. Saltresponsive mechanisms in chromosome segment substitution lines of rice (Oryza sativa L. CV. KDML105). Plant Physiol Biochem. 2016;103:96-105.

63. Dionisio-Sese ML, Tobita S. Effects of salinity on sodium content and photosynthetic responses of rice seedlings differing in salt tolerance. J Plant Physiol. 2000;157:54-8.

64. Wang X, Wang W, Huang J, Peng S, Xiong D. Diffusional conductance to $\mathrm{CO} 2$ is the key limitation to photosynthesis in salt-stressed leaves of rice (Oryza sativa). bioRxiv; 2017. 
65. Moradi F, Ismail AM. Responses of photosynthesis, chlorophyll fluorescence and ROS-scavenging systems to salt stress during sedling and reproductive stages in rice. Ann Bot. 2007;99:1161-73.

66. Ueda Y, Frimpong F, Qi Y, Matthus E, Wu L, Höller S, Kraska T, Frei M. Genetic dissection of ozone tolerance in rice (Oryza sativa L.) by a genomewide association study. J Exp Bot. 2015;66:293-306.

67. Lipka AE, Kandianis CB, Hudson ME, Yu J, Drnevich J, Bradbury PJ. From association to prediction: statistical methods for the dissection and selection of complex traits in plants. Curr Opin Plant Biol. 2015;24:110-8.

68. Hamblin MT, Buckler ES, Jannink JL. Population genetics of genomics-based crop improvement methods. Trends Genet. 2011;27:98-106.

69. Myles S, Peiffer J, Brown PJ, Ersoz ES, Zhang Z, Costich DE, Buckler ES. Association mapping: critical considerations shift from genotyping to experimental design. Plant Cell. 2009;21:2194-202.

70. Tarchini R, Biddle P, Wineland R, Tingey S, Rafalski A. The complete sequence of $340 \mathrm{~kb}$ of DNA around the rice Adh1-Adh2 region reveals interrupted colinearity with maize chromosome 4. Plant Cell. 2000;12:381-91.

71. Chen M, SanMiguel P, de Oliveira AC, Woo SS, Zhang H, Wing RA, Bennetzen JL. Microcolinearity in sh2-homologous regions of the maize, rice, and sorghum genomes. PNAS. 1997;94:3431-5.

72. Liu H, Sachidanandam R, Stein L. Comparative genomics between rice and Arabidopsis shows scant collinearity in gene order. Genome Res. 2001;11: 2020-6.

73. Bimpong IK, Manneh B, Diop B, Ghislain K, Sow A, Amoah NKA, Gregorio G, Singh RK, Ortiz R, Wopereis M. New quantitative trait loci for enhancing adaptation to salinity in rice from Hasawi, a Saudi landrace into three african cultivars at the reproductive stage. Euphytica. 2014;200:45-60.

74. Qiu X, Yuan Z, Liu H, Xiang X, Yang L, He W, Du B, Ye G, Xu J, Xing D, et al. Identification of salt tolerance-improving quantitative trait loci alleles from a salt-susceptible rice breeding line by introgression breeding. Plant Breed. 2015;134:653-60

75. Lin HX, Zhu MZ, Yano M, Gao JP, Liang ZW, Su WA, Hu XH, Ren ZH, Chao DY. QTLs for $\mathrm{Na}+$ and $\mathrm{K}+$ uptake of the shoots and roots controlling rice salt tolerance. Theor Appl Genet. 2004;108:253-60.

76. Lee SY, Ahn JH, Cha YS, Yun DW, Lee MC, Ko JC, Lee KS, Eun MY. Mapping QTLs related to salinity tolerance of rice at the young seedling stage. Plant Breed. 2007;126:43-6.

77. Yao M, Wang J, Chen $\mathrm{H}$, Zhang $\mathrm{H}$. Inheritance and QTL mapping of salt tolerance in rice. Rice Sci. 2005;12:25-32.

78. Takehisa H, Shimodate T, Fukuta Y, Ueda T, Yano M, Yamaya T, Kameya T, Sato T. Identification of quantitative trait loci for plant growth of rice in paddy field flooded with salt water. Field Crops Res. 2004;89:85-95.

79. Wang Z, Cheng J, Chen Z, Huang J, Bao Y, Wang J, Zhang H. Identification of QTLs with main, epistatic and QTL x environment interaction effects for salt tolerance in rice seedlings under different salinity conditions. Theor Appl Genet. 2012;125:807-15.

80. Sabouri H, Sabouri A. New evidence of QTLs attributed to salinity tolerance in rice. Afr J Biotechnol. 2008;7:4376-83.

81. Hoang MT, Tran NT, Nguyen KT, Williams B, Wurm P, Bellairs S, Mundree S. Improvement of salinity stress tolerance in rice: challenges and opportunities. Agronomy. 2016;6:54.

82. Sinha AK, Jaggi M, Raghuram B, Tuteja N. Mitogen-activated protein kinase signaling in plants under abiotic stress. Plant Signal Behav. 2011;6:196-203.

83. Kovtun Y, Chiu WL, Tena G, Sheen J. Functional analysis of oxidative stressactivated mitogen-activated protein kinase cascade in plants. PNAS. 2000;97: 2940-5.

84. Preston JC, Hileman LC. Functional evolution in the plant SQUAMOSAPROMOTER BINDING PROTEIN-LIKE (SPL) gene family. Front Plant Sci. 2013;4:80

85. Xie K, Wu C, Xiong L. Genomic organization, differential expression, and interaction of SQUAMOSA promoter-binding-like transcription factors and microRNA156 in rice. Plant Physiol. 2006;142:280.

86. Mao HD, Yu LJ, Li ZJ, Yan Y, Han R, Liu H, Ma M. Genome-wide analysis of the SPL family transcription factors and their responses to abiotic stresses in maize. Plant Gene. 2016;6:1-12.

87. Schuler MA, Werck-Reichhart D. Functional genomics of P450s. Annu Rev Plant Biol. 2003:54:629-67.

88. Werck-Reichhart D, Feyereisen R. Cytochromes P450: a success story. Genome Biol. 2000;1:reviews3003.1.

89. Narusaka Y, Narusaka M, Seki M, Umezawa T, Ishida J, Nakajima M, Enju A, Shinozaki K. Crosstalk in the responses to abiotic and biotic stresses in
Arabidopsis: analysis of gene expression in cytochrome P450 gene superfamily by cDNA microarray. Plant Mol Biol. 2004;55:327-42.

90. Mao G, Seebeck T, Schrenker D, Yu O. CYP709B3, a cytochrome P450 monooxygenase gene involved in salt tolerance in Arabidopsis thaliana. BMC Plant Biol. 2013;13:169.

91. Tamiru M, Undan JR, Takagi H, Abe A, Yoshida K, Undan JQ, Natsume S, Uemura A, Saitoh H, Matsumura H, et al. A cytochrome P450, OsDSS1, is involved in growth and drought stress responses in rice (Oryza sativa L.) Plant Mol Biol. 2015:88:85-99.

92. Wang C, Yang Y, Wang H, Ran X, Li B, Zhang J, Zhang H. Ectopic expression of a cytochrome P450 monooxygenase gene PtCYP714A3 from Populus trichocarpa reduces shoot growth and improves tolerance to salt stress in transgenic rice. Plant Biotechnol J. 2016;14:1838-51.

93. Zhou S, Sun X, Yin S, Kong X, Zhou S, Xu Y, Luo Y, Wang W. The role of the F-box gene TaFBA1 from wheat (Triticum aestivum L.) in drought tolerance. Plant Physiol Biochem. 2014;84:213-23.

94. Jain M, Nijhawan A, Arora R, Agarwal P, Ray S, Sharma P, Kapoor S, Tyagi AK, Khurana JP. F-box proteins in rice. Genome-wide analysis, classification, temporal and spatial gene expression during panicle and seed development, and regulation by light and abiotic stress. Plant Physiol. 2007;143:1467.

95. Jia FJ, Wang CY, Huang JG, Yang GD, Wu CG, Zheng CC. SCF E3 ligase PP2-B11 plays a positive role in response to salt stress in Arabidopsis. J Exp Bot. 2015;66:4683-97.

96. Gonzalez LE, Keller K, Chan KX, Gessel MM, Thines BC. Transcriptome analysis uncovers Arabidopsis F-BOX STRESS INDUCED 1 as a regulator of jasmonic acid and abscisic acid stress gene expression. BMC Genomics. 2017;18:533.

97. Yan YS, Chen XY, Yang K, Sun ZX, Fu YP, Zhang YM, Fang RX. Overexpression of an F-box protein gene reduces abiotic stress tolerance and promotes root growth in rice. Mol Plant. 2011;4:190-7.

98. Lyzenga WJ, Stone SL. Abiotic stress tolerance mediated by protein ubiquitination. J Exp Bot. 2012:63:599-616.

99. Stone SL, Callis J. Ubiquitin ligases mediate growth and development by promoting protein death. Curr Opin Plant Biol. 2007:10:624-32.

100. Xu G, Ma H, Nei M, Kong H. Evolution of F-box genes in plants: different modes of sequence divergence and their relationships with functional diversification. PNAS. 2009;106:835-40

101. Xu GY, Cui YC, Wang ML, Li MJ, Yin XM, Xia XJ. OsMsr9, a novel putative rice F-box containing protein, confers enhanced salt tolerance in transgenic rice and Arabidopsis. Mol Breed. 2014;34:1055-64.

102. Persson Ö, Valadi $\AA$, Nyström T, Farewell A. Metabolic control of the Escherichia coli universal stress protein response through fructose-6phosphate. Mol Microbiol. 2007:65:968-78.

103. Ndimba BK, Chivasa S, Simon WJ, Slabas AR. Identification of Arabidopsis salt and osmotic stress responsive proteins using two-dimensional difference gel electrophoresis and mass spectrometry. Proteomics. 2005;5:4185-96.

104. Sauter M, Rzewuski G, Marwedel T, Lorbiecke R. The novel ethylene-regulated gene OsUsp 1 from rice encodes a member of a plant protein family related to prokaryotic universal stress proteins. J Exp Bot. 2002:53:2325-31.

105. Jung YJ, Melencion SM, Lee ES, Park JH, Alinapon CV, Oh HT, Yun DJ, Chi YH, Lee SY. Universal stress protein exhibits a redox-dependent chaperone function in Arabidopsis and enhances plant tolerance to heat shock and oxidative stress. Front Plant Sci. 2015;6:1141.

106. Ammar MHM, Singh RK, Singh AK, Mohapatra T, Sharma TR. N.K. S. Mapping QTLS for salinity tolerance at seedling stage in rice (Oryza sativa L.). In: African crop science conference proceedings; 2007. p. 617-20.

107. Hossain H, Rahman MA, Alam MS, Singh RK. Mapping of quantitative trait loci associated with reproductive-stage salt tolerance in rice. J Agron Crop Sci. 2015;201:17-31.

108. Jl L, Yp Q, Cg Y, Xd M, Gl C, Zw Z, Zhang Sy ZT, Lz H. Identification of QTLs associated with salt or alkaline tolerance at the seedling stage in rice under salt or alkaline stress. Euphytica. 2014;201:441-52.

109. Prasad SR, Bagali PG, Hittalmani S, Shashidhar HE. Molecular mapping of quantitative trait loci associated with seedling tolerance to salt stress in rice (Oryza sativa L.). Curr Sci. 2000;78:162-4.

110. UI Haq T, Gorham J, Javaid A, Akhtar N, Steele K. Dynamic quantitative trait loci for salt stress components on chromosome 1 of rice. Funct Plant Biol. 2010;37:634-45

111. Karen Y. Oróstica, Ricardo A. Verdugo, (2016) chromPlot: visualization of genomic data in chromosomal context. Bioinformatics 32 (15):2366-8. 